\title{
Coastal wave reflection, directional spread, and seismoacoustic noise sources
}

\author{
Fabrice Ardhuin ${ }^{1}$ and Aron Roland ${ }^{2}$ \\ Received 14 December 2011; revised 11 May 2012; accepted 15 May 2012; published 26 June 2012.
}

[1] Coastal reflection is introduced in a phase-averaged numerical wave model, first with a constant coefficient, and then with a reflection coefficient defined from the shoreface slope and that depends on the incident wave height and mean frequency. This parameterization is used in both regular and unstructured grids. The calibration involves a site-specific shoreface slope that is associated with the local geomorphology of the shoreline. Using wave buoy data off Hawaii and the U.S. West Coast, it is found that coastal reflection is necessary to reproduce observed directional properties of coastal sea states. Errors on the mean directional spread are reduced by up to $30 \%$ for the frequency band 0.04 to $0.30 \mathrm{~Hz}$ with, at most locations, very little impact on the mean direction and energy levels. The most accurate results are obtained using the parameterization based on the shoreface slope, provided that this slope is estimated accurately. These parameterizations are validated using seismic noise data. Using data from the U.S. West Coast it is shown that the reflection defined from the shoreface slope can improve the correlation between measured and modeled seismic noise.

Citation: Ardhuin, F., and A. Roland (2012), Coastal wave reflection, directional spread, and seismoacoustic noise sources, J. Geophys. Res., 117, C00J20, doi:10.1029/2011JC007832.

\section{Introduction}

[2] Wave reflection at the shoreline is an important aspect of harbor agitation models [e.g., Biesel and Ranson, 1961], and many investigations have been performed in this context. The reflection properties along a one-dimensional wave flume are relatively well known [e.g., Taira and Nagata, 1968]. For natural shorelines, field experiments have generally focused on the scale of a few kilometers from beaches [Nelson and Gonsalves, 1990; Elgar et al., 1994], with very few studies on the effects of reflection on the on directional wave spectra and wave properties at larger scales [O'Reilly et al., 1999]. Although reflection is generally weak on natural beaches, typically less that $5 \%$ of the wind sea and swell wave energy [Elgar et al., 1994], it can still have a profound impact on beach morphodynamics due to partial standing waves [Yu and $\mathrm{Mei}, 2000]$. For shorelines with steep cliffs, energy reflection coefficients $R^{2}$ up to $40 \%$ have been reported by O'Reilly et al. [1999], which can lead to an important increase in wave height in otherwise sheltered areas. Reflection is also very important for the wave directional spectrum, $F(f, \theta)=E(f) M(f, \theta)$, where $M(f, \theta)$ is a normalized directional distribution such that the integral of $M$ over directions is equal to 1.

\footnotetext{
${ }^{1}$ Laboratoire d'Océanographie Spatiale, Ifremer, Plouzane, France.

${ }^{2}$ Institute for Hydraulic and Water Resources Engineering, Technische Universität Darmstadt, Darmstadt, Germany.

Corresponding author: F. Ardhuin, Laboratoire d'Océanographie Spatiale, Ifremer, Centre de Brest, BP 70, Plouzane F-29280, France. (ardhuin@ifremer.fr)

(C)2012. American Geophysical Union. All Rights Reserved. 0148-0227/12/2011JC007832
}

[3] Finally, reflection generally enhances the second-order pressure spectrum at very small wave numbers by several orders of magnitude. Indeed, this part of the second-order spectrum can be interpreted as the interference of pairs of linear wave trains with nearly opposite wave numbers $\mathbf{k}$ and $\mathbf{k}^{\prime}$ giving rise to very long components of wave number $\mathbf{k}_{2}=\mathbf{k}+\mathbf{k}^{\prime}$ with $k_{2} \ll k$ and $f_{2}=f+f^{\prime} \simeq 2 f$. The second-order wave equation is forced by an equivalent surface pressure spectrum $F_{p 3 D}$ which, when $k_{2} \ll k$, is the source of forced gravity wave motions and seismic waves because $2 \pi f_{2} / k_{2}$ can match the phase speed of seismic waves, of the order of a few kilometers per second [Hasselmann, 1963]. In deep water, this pressure spectrum takes the form [Ardhuin et al., 2011a]

$$
F_{p 3 D}\left(f_{2}=2 f, \mathbf{k}_{2} \simeq 0\right)=\rho_{w}^{2} g^{2} f_{2} E^{2}(f) I(f),
$$

where $f_{2}$ and $\mathbf{k}_{2}=\left(k_{2 x}, k_{2 y}\right)$ are the frequency and wave number vector of the second-order pressure spectrum. The " $3 \mathrm{D}$ " in $F_{p 3 D}$ is there to remind that this is a spectral density in a three-dimensional space $\left(f_{2}, k_{2 x}, k_{2 y}\right)$, with units of $\mathrm{Pa}^{2} \mathrm{~m}^{2} \mathrm{~s}$. The nondimensional directional integral $I$ is given by

$$
I(f)=\int_{0}^{\pi} M(f, \theta) M(f, \theta+\pi) \mathrm{d} \theta .
$$

[4] As illustrated by Figure 1, even a few percent of shoreline reflection is enough to dramatically increase the directional integral $I$. As a result, the second-order pressure is very sensitive to shoreline reflections. This pressure signal, can be recorded at large depths compared to the wavelength [e.g., Herbers and Guza, 1994; Farrell and Munk, 2010] and it is the source of seismic noise and infrasounds 

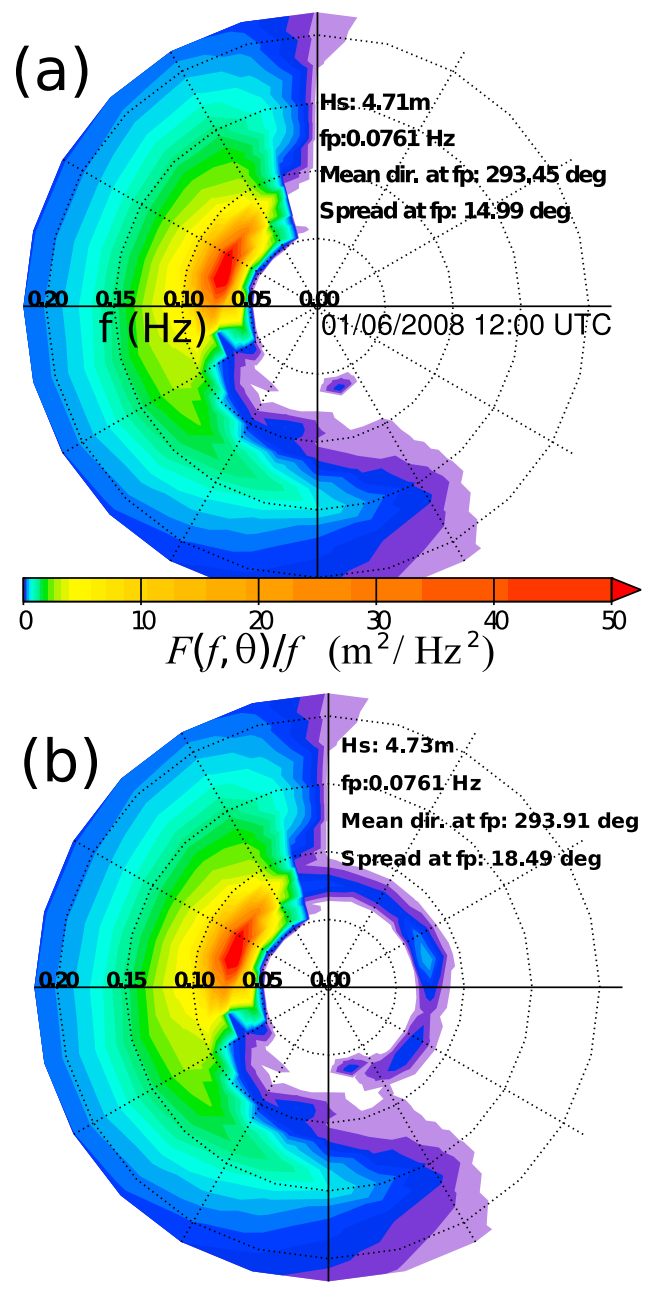

Figure 1. Example of modeled directional wave spectra at the location of buoy 46214 , located $40 \mathrm{~km}$ offshore of Point Reyes, near San Francisco. (a) Model result without coastal reflection, and (b) model result with coastal reflection, using a $10 \%$ reflection at the shoreline. In the case of Figure $1 \mathrm{~b}$, the offshore propagating energy only accounts for $1 \%$ of the total energy, but the directional spread at the peak frequency $\left(f_{p}=0.076 \mathrm{~Hz}\right)$ has increased from $15^{\circ}$ to $18.5^{\circ}$, while the directional integral $I(f)$ defined by equation (2) for that same frequency is multiplied by a factor 60 , at 0.0028 . Wave energy is shown in the direction from which the waves are coming.

[Hasselmann, 1963; Szelwis, 1982; Kedar et al., 2008; Ardhuin et al., 2011a; Stopa et al., 2010].

[5] The investigation of these noises thus requires a careful modeling of shoreline reflection. Another important reason to improve the parameterization of shoreline reflection is the implementation of extended Wave Action Equation that accounts for higher-order depth and current gradients [Holthuijsen et al., 2003; Liau et al., 2011; Toledo et al., 2012]. In that context, the phase velocities depend strongly on the spatial gradients of the wave action which can be strongly overpredicted at locations where wave reflection is significant. Finally, the sensitivity of radiation stresses on the directional distribution may lead to a significant effect of coastal reflections on coastal morphodynamics.
[6] Most previous modeling efforts related to wave reflection have used a bottom-up approach, with measured or modeled local effects [e.g., Ilic et al., 2007]. Reflection has already been introduced before in other models such TOMAWAC [Benoit et al., 1996] SWAN [Booij et al., 1999], or WAVEWATCH III $^{(\mathrm{R})}$ [Ardhuin et al., 2011a]. In these models the reflection coefficient was generally taken constant and provided by the user. However, an important difficulty is the variability of this reflection and, for natural shorelines, its determination from the local geomorphology. Here we rather take a top-down perspective, and estimate the shoreline reflection based on what is missing in model results without reflections, when compared to directional buoy data. In particular, we show that the reflection coefficient may be determined from the slope of the beach or cliff at the land-sea interface. The methods presented here are applicable to any phase-averaged spectral wave model.

[7] Here we shall use the WAVEWATCH III $^{(\mathrm{R})}$ code version 4.04 [Tolman et al., 2011], using either third-order Ultimate Quickest scheme with garden sprinkler effect reduction [Leonard, 1991; Tolman, 2002] for regular grids, or the narrow stencil ( $\mathrm{N}$ for short) scheme on unstructured grids [Csík et al., 2002; Roland, 2008; Roland et al., 2009]. In both cases we use the TEST441b parameterization for the wave generation and dissipation [Ardhuin et al., 2009, 2010], combined with the Discrete Interaction Approximation (DIA) for the nonlinear wave evolution [Hasselmann et al., 1985].

[8] Because there are few available measurements of bottom pressure in deep water, and because the analysis of seismic noise is complicated by the poorly known seismic propagation, we will first focus on directional spread estimations from surface buoys and modeled spectra. The cospectra of vertical and horizontal displacements (or slopes) recorded by a buoy gives frequency-dependent moments

$$
\begin{aligned}
& a_{1}(f)=\frac{C_{x z}(f)}{\sqrt{C_{z z}(f)\left[C_{x x}(f)+C_{y y}(f)\right]}}, \\
& b_{1}(f)=\frac{C_{y z}(f)}{\sqrt{C_{z z}(f)\left[C_{x x}(f)+C_{y y}(f)\right]}},
\end{aligned}
$$

where $C_{x z}$ is the cospectrum of $x$ and $z$ buoy displacements, with similar notations for the other cospectra [e.g., Kuik et al., 1988].

[9] For any frequency band $\left[f_{1}, f_{2}\right]$ we can integrated these moments and relate them to the directional spectrum

$$
\begin{aligned}
a_{1} & =\int_{f_{1}}^{f_{2}} E(f) a_{1}(f) \mathrm{d} F / \int_{f_{1}}^{f_{2}} E(f) \mathrm{d} F \\
& =\int_{f_{1}}^{f_{2}} \int_{0}^{2 \pi} \cos (\theta) E(f) M(f, \theta) \mathrm{d} \theta \mathrm{d} F / \int_{f_{1}}^{f_{2}} E(f) \mathrm{d} f, \\
b_{1} & =\int_{f_{1}}^{f_{2}} E(f) b_{1}(f) \mathrm{d} F / \int_{f_{1}}^{f_{2}} E(f) \mathrm{d} F \\
& =\int_{f_{1}}^{f_{2}} \int_{0}^{2 \pi} \sin (\theta) E(f) M(f, \theta) \mathrm{d} \theta \mathrm{d} F / \int_{f_{1}}^{f_{2}} E(f) \mathrm{d} f .
\end{aligned}
$$


Table 1. Statistics for Model Errors on the Directional Spread Over the Year 2008, Estimated for the Frequency Band 0.04 to $0.36 \mathrm{~Hz}^{\mathrm{a}}$

\begin{tabular}{cccccccc}
\hline & \multicolumn{3}{c}{$R^{2}=0$} & & \multicolumn{3}{c}{$R^{2}=0.1$} \\
\cline { 2 - 3 } \cline { 6 - 7 } Buoy & Bias (deg) & NE (\%) & $r$ & & Bias (deg) & NE (\%) & $r$ \\
\hline 51001 & 0.9 & 7.8 & 0.92 & & 1.0 & 7.9 & 0.92 \\
51201 & -4.5 & 20.3 & 0.70 & & 2.2 & 14.6 & 0.76 \\
51202 & 3.0 & 16.3 & 0.73 & & 4.74 & 17.76 & 0.72 \\
46041 & -0.9 & 17.0 & 0.74 & & 1.4 & 17.3 & 0.74 \\
46211 & -6.4 & 24.2 & 0.75 & & -3.7 & 16.8 & 0.80 \\
46050 & -3.4 & 20.8 & 0.63 & & 0.2 & 17.0 & 0.66 \\
46229 & -5.0 & 19.8 & 0.80 & & -2.0 & 14.2 & 0.82 \\
46212 & -6.1 & 25.0 & 0.64 & & 1.7 & 14.2 & 0.69 \\
46022 & -0.7 & 23.6 & 0.46 & & 3.2 & 24.3 & 0.51 \\
46214 & -5.6 & 20.9 & 0.82 & & -3.6 & 16.8 & 0.84 \\
46013 & -13.0 & 37.1 & 0.71 & & -8.6 & 27.4 & 0.75 \\
46236 & -7.8 & 33.2 & 0.73 & & 1.7 & 19.5 & 0.74 \\
46042 & -6.6 & 25.3 & 0.77 & & -4.2 & 20.6 & 0.78 \\
46028 & -1.9 & 25.2 & 0.68 & & 0.2 & 24.1 & 0.69 \\
46011 & -9.0 & 28.7 & 0.71 & & -4.7 & 20.4 & 0.71 \\
46219 & 0.9 & 15.2 & 0.82 & & 1.5 & 15.4 & 0.83 \\
46234 & -5.0 & 21.1 & 0.44 & & 2.8 & 16.0 & 0.58 \\
46221 & -5.7 & 20.5 & 0.72 & & -0.4 & 14.3 & 0.68 \\
46223 & -3.4 & 16.1 & 0.62 & & 2.3 & 14.2 & 0.62 \\
46224 & -2.9 & 14.2 & 0.69 & & 2.4 & 13.3 & 0.66 \\
46225 & -2.2 & 13.5 & 0.80 & & 4.5 & 16.7 & 0.77 \\
46232 & -2.0 & 12.7 & 0.86 & & 1.6 & 11.4 & 0.85 \\
\hline
\end{tabular}

${ }^{\text {a }}$ See Figures 1 and 2 for the buoy locations. All buoy spread estimates were computed from 3 hourly averaged directional moments $a_{1}$ and $b_{1}$, and statistics are estimated only from records for which the mean wave directions is within $90^{\circ}$ of the normal to the nearest coast. The normalized root-mean-square error (NE) is defined as the root-mean-square error divided by the root-mean-square observed value. The coefficient $r$ is Pearson's linear correlation coefficient.

From these, the directional spread is defined by

$$
\sigma_{1}=\sqrt{2\left[1-\sqrt{a_{1}^{2}+b_{1}^{2}}\right]} .
$$

This spread is thus derived from the cospectra of buoy motions along the three axes $x, y$, and $z$.

[10] Some wave measuring devices are known to produce biases on the directional spread $\sigma_{1}$ of the order of $5^{\circ}$ [O'Reilly et al., 1996]. This is why we attempt to use data only from the same type of buoy, namely directional Datawell Waveriders, such as the buoys 512xx and 462xx, with some complements provided by $3 \mathrm{~m}$ diameter discus-shaped buoys $510 \mathrm{xx}$ and 460xx.

[11] The wave model is applied with a discretization into 24 directions, and 31 exponentially spaced frequencies from 0.037 to $0.72 \mathrm{~Hz}$. We focus on Hawaii and the U.S. West coast in order to minimize potential analysis errors associated with shallow water propagation effects over broad shelves [Ardhuin et al., 2003; Ardhuin and Magne, 2007]. For the same reasons we also avoid areas with strong currents induced by rivers. In the case of Hawaii, reflection is found to have no discernible effect at buoy 51001 (Table 1, see location on Figure 2). The result is the same for the other deep water buoys 51002-51004, but there is a clear effect at the coastal buoys 51201 and 51202 .

[12] Using the wave model to estimate the coastal reflection does not mean that we have a blind faith in the model or in the buoy data. In fact, we know quite well that the DIA leads to positive biases in the directional spread that are partly compensated by errors in the other parameterizations [e.g., Banner and Young, 1994; Ardhuin et al., 2007]. Also, the spectra recorded by buoys contain nonlinear contributions, which broaden the spectrum at low frequencies [e.g., Krogstad and Trulsen, 2010], an effect that we do not include in our wave model.

[13] Even with these imperfections, a first crude parameterization of shoreline reflection, with a constant coefficient, can improve dramatically the modeled directional properties and associated seismic noise in regions where we expect a significant reflection. This was shown by Ardhuin et al. [2011a] with a strong reduction of root-mean-square errors on $\sigma_{1}$ in winters at the central California buoy 46214, and a more than doubling of the linear correlation from $r=0.4$ to $r=0.88$ for seismic noise recorded by the Berkeley seismic station. This impact of reflection is here put in a broader context by expanding to other locations in Table 1 (see Figures 2 and 3 for locations). The improvement is mostly visible for buoys 51201, 46211, 46229, 46013, 46011, whereas there is almost no impact for buoys 51001, 46041, 46028 , from which we may conclude that reflection is not important at these latter locations. On the contrary, the model results are degraded at buoys 51202, 46022, 46219, which may indicate that, for these other locations, the energy reflection coefficient $R^{2}$ should be less than 0.1 .

[14] This leads us to propose, in section 2 , a refined parameterization for shoreline reflection, applicable to classical rectangular grids or triangle-based meshes. This parameterization is calibrated in sections 3 and 4, using directional wave buoy data. Finally, we discuss the impact of this parameterization on seismic noise estimates, via the secondorder pressure spectrum.

\section{Numerical Implementation of Shoreline Reflection}

\subsection{General Numerical Principles}

[15] Coastal reflection has been implemented in the version 4.04 of WAVEWATCH III ${ }^{(\mathrm{R})}$, in the form of a source term on the right hand side of the wave action equation [e.g., WISE Group, 2007]. This parameterization will be available in the next release of the code, and is activated by using the switch REF1. The different choices in parameterization, from a constant reflection coefficient to an amplitude and location-dependent reflection is performed via name list parameters.

[16] The actual treatment of the reflection source term differs between finite difference grids, in which the boundary is between nodes, and triangle-based meshes for which the boundary goes through the nodes. In the finite difference grid, the boundary condition for the advection scheme is unchanged, and the source term is designed to add the energy in direction $\theta$ that is latter propagated away from the boundary by the advection scheme. This gives

$$
\begin{aligned}
S_{\text {ref,rect }}(f, \theta)= & \int_{0}^{2 \pi} R^{2}\left(f, \theta, \theta^{\prime}\right) \frac{C_{g}(k)}{\Delta x \Delta y} N\left(f, \theta^{\prime}\right) \\
& \times\left[s_{x} \cos \theta \Delta y+s_{y} \sin \theta \Delta x\right] \mathrm{d} \theta^{\prime},
\end{aligned}
$$

where $R^{2}$ is an energy reflection coefficient, $\Delta x$ and $\Delta y$ are the grid spacing along the two axes, $\theta^{\prime}$ is the incident direction and 


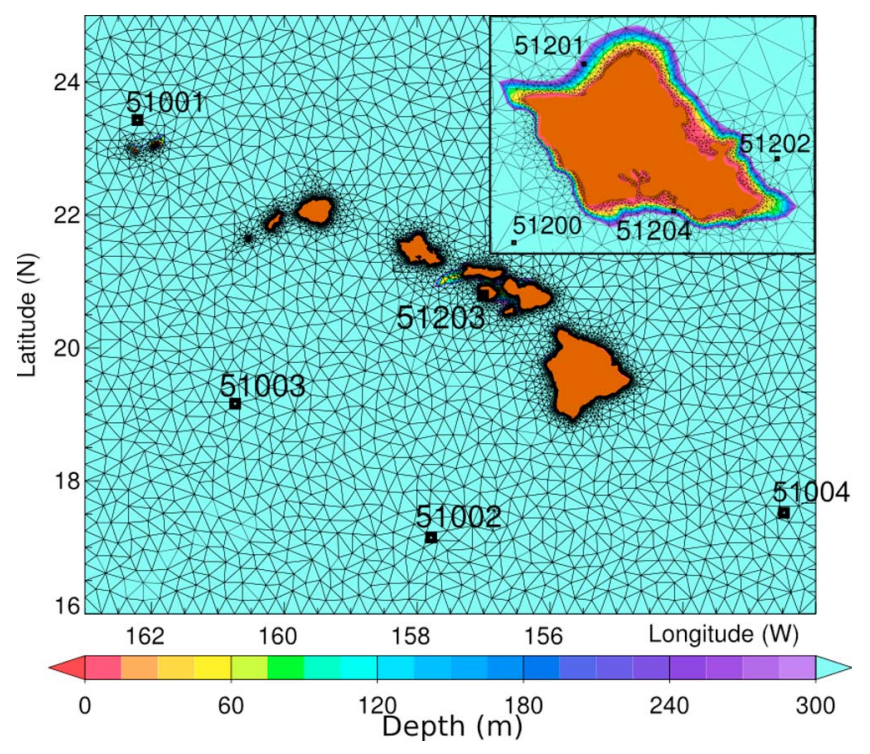

Figure 2. Model mesh for the Hawaiian islands, with the location of the buoys used for validation. The inset shows the mesh details around Oahu.

$\theta$ is the reflected direction. The switch $s_{x}$ is 1 if the point where the source term is estimated has a land neighbor in the $x$ direction, and $s_{x}=0$ otherwise. Similarly, $s_{y}=1$ if the point where the source term is estimated has a land neighbor in the $y$ direction, and $s_{y}=0$ otherwise. An example is shown on Figure 4.

[17] In the case of triangle-based meshes, for each node on the boundary, wave directions that are coming in a wet triangle, are taken as incident directions, whereas directions that are coming through a dry triangle are taken to be the reflected directions. For a straight coast this separation between incident and reflected components is straightforward. For coastlines that make a sharp angle at the coast, this leads to a narrow range of reflected directions, which is less realistic. The boundary condition is enforced differently for the two types of directions. The spectral density in the reflected directions is defined in terms of a Dirichlet boundary condition equal to the value given, at the beginning of the advection step, by the previous source term integration step. As a result, the use of a source term is equivalent to a direct forcing of the wave action spectrum $N$ to the reflected value

$$
N_{\text {ref,unst }}(f, \theta)=\int_{0}^{2 \pi} R^{2}\left(f, \theta, \theta^{\prime}\right) N\left(f, \theta^{\prime}\right) \mathrm{d} \theta^{\prime},
$$

where $R^{2}$ is an energy reflection coefficient, $\theta^{\prime}$ is the incident direction and $\theta$ is the reflected direction.

\subsection{Shoreline Geometry}

[18] Two properties of the shoreline are used to define $R^{2}$. These are the normal to the shoreline $\theta_{n}$, and the variability of this normal, which is used to classify the coastline geometry in three categories: straight coast, mild corner, or sharp corner. Indeed, whereas the reflection of waves has been observed to be specular for plane and parallel contours, the bathymetry and shoreline are generally not uniform at resolutions coarser than a few hundred meters, as used here. Following what had been done in the SWAN model, the reflected energy is redistributed in directions around the specular direction, which is a way to represent the variability of the shoreline directions. We thus use

$$
R^{2}\left(f, \theta, \theta^{\prime}\right)=\max \left\{R_{0}^{2}\left(f, \theta^{\prime}\right) A_{n} \cos ^{m}\left(\theta-\theta_{s}\right), 0\right\},
$$

where $\theta_{s}$ is the specular reflection direction, such that $\theta_{s}-\left(\theta_{n}+\pi\right)=\theta^{\prime}-\theta_{n}$, as illustrated on Figure 4 .

[19] The exponent $m$ is taken to be a function of the shoreline category. We have arbitrarily taken $m=4$ for a straight shoreline, $m=2$ for a mild corner and $m=0$ for a sharp corner or a subgrid obstacle. We have tested the impact of these thresholds by changing the exponent $m$ in equation (10) from 4 to 20 for a straight coastline. At the location of buoy 46214, off central California, this only increased $\sigma_{1}$ by $0.2 \%$, compared to a $8 \%$ change between the model without reflection and the model with a constant $R_{0}^{2}=0.1$. We have thus kept $m=4$.

[20] The associated normalization constant in equation (10) is

$$
A_{n}=2 /\left(\sum_{j=1}^{N_{\theta}}\left|\cos ^{n}\left(\theta_{j}\right)\right| \frac{2 \pi}{N_{\theta}}\right),
$$

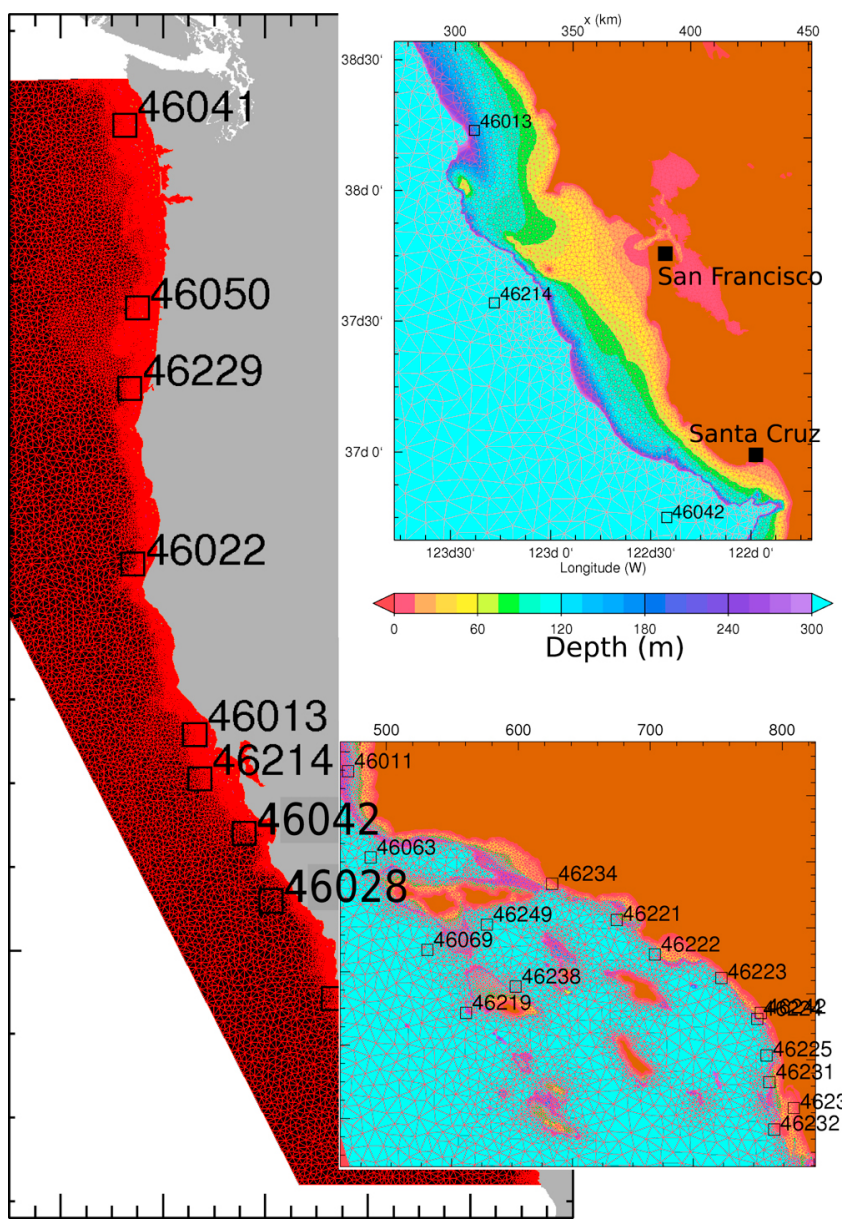

Figure 3. Model mesh for the U.S. West Coast, with the location of the buoys used for validation. The insets show the mesh details for central California coast and around buoy 46232 offshore of San Diego. 


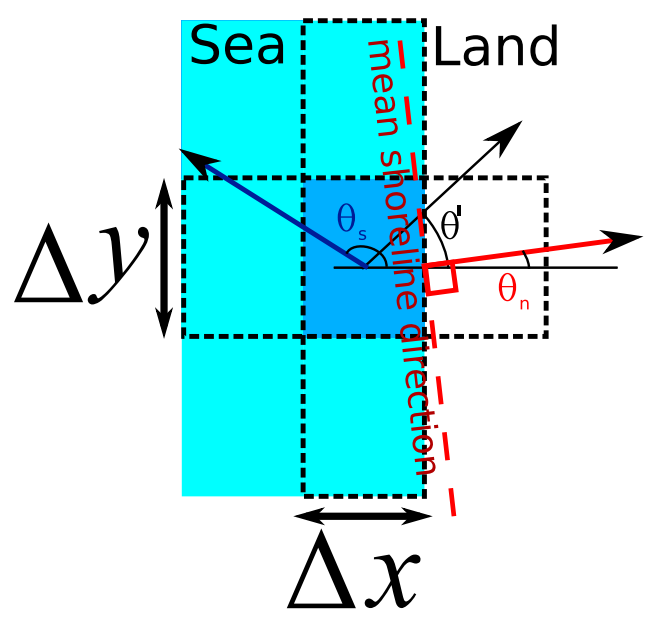

Figure 4. Details of the numerical scheme on regular grids and elations between the incident angle $\theta^{\prime}$; the shore-normal direction $\theta_{n}$ is in red, and the specular direction $\theta_{s}$ is in dark blue. In the central model cell (darker blue) where the reflection is estimated, there is only one land neighbor to the right. In the present case, $s_{x}=1$ and $s_{y}=0$, so that equation (8) takes the action flux going to land $N\left(f, \theta^{\prime}\right) \cos \theta^{\prime} \Delta y$ and redistributes it over the area of the cell $\Delta x \Delta y$ and in reflected directions $\theta$ with a coefficient $R^{2}\left(f, \theta, \theta^{\prime}\right)$. For a straight shoreline the reflection coefficient is maximum in the reflected direction equal to $\theta_{s}$.

where $N_{\theta}$ are the number of discrete directional bins (here $\left.N_{\theta}=24\right)$, and $2 \pi / N_{\theta}$ is the angle increment. The normalization given by equation (11) is such that the integral of $R^{2}\left(f, \theta, \theta^{\prime}\right)$ over 180 degrees in the reflected directions is equal to $R_{0}^{2}\left(f, \theta^{\prime}\right)$, the ratio of the reflected to the incident energy for the incident component $\left(f, \theta^{\prime}\right)$. In our first tests we have taken a constant $R_{0}^{2}\left(f, \theta^{\prime}\right)=0.1$.

[21] For rectangular grids, the definition of the shoreline direction from the land/sea mask is explained by Ardhuin et al. [2011a], and illustrated in Figure 5. For unstructured grids, the nodes are on the boundary and thus the shoreline orientation is simply given by the orientation of vertices joining boundary nodes. Because the shoreline orientation must be defined at the node, where the spectrum and source terms are evaluated, it is taken as the vector average of the directions of the two shoreline vertices that are connected to each node. The categories of shoreline are defined with two thresholds for the jump inshoreline orientations at the node. If the jump is less than $45^{\circ}$, the shoreline is considered straight, and if the jump is more than $110^{\circ}$ this is considered a sharp angle. Obviously, these thresholds should be a function of the shoreline resolution relative to the wavelength of the ocean waves. For example, a very well refined shoreline will always give a locally straight coast. Here we have not considered this complication.

\subsection{Effects of Water Depths Near the Shoreline}

[22] An important practical aspect for the numerical model is the actual depth at which the reflection coefficient is estimated. Figure 6 illustrates why the reflection coefficient $R_{0}^{2}\left(f, \theta^{\prime}\right)$ is generally a function of the water depth at which it is evaluated and the depth gradients near the shoreline. Typically the incident wave direction $\theta^{\prime}$ becomes closer to shore normal as waves approach the shore, and the energy of these incoming waves is modified by refraction and bottom friction, but also wave breaking in the surf zone. Indeed, most of the reflection is expected to occur right at the shoreline, after the incoming wave height has been affected by breaking. In the case of the spectrum shown in Figure $1 \mathrm{~b}$, the specified $R^{2}$ at the shore is 0.1 , but, in this particular case it is reduced to 0.01 when estimated at the buoy location, $40 \mathrm{~km}$ from land. This may not be typical, but it can happen.

[23] This reduction of the effective reflection coefficient with depth, is due to a reduction in both the offshore propagating wave energy, largely due to trapping by refraction, and a reduction of incoming wave energy from offshore to the shoreline, due to sheltering effects and also refraction. Here we shall base our amplitude-dependent parameterization of reflection on the field measurements by Elgar et al. [1994], made in $13 \mathrm{~m}$ of water in front of a beach with depth contours nearly uniform in the alongshore direction. Since the observation suggest that $R^{2}$ is inversely proportional to the wave energy, i.e., the significant wave height squared $H_{s}^{2}$, the influence of wave height is limited because the reflected energy, proportional to $R^{2} H_{s}^{2}$ is almost constant. However, over a sloping bottom, the directional distribution of the offshore propagating waves may be strongly affected by the depth at which the reflected spectrum is prescribed.

[24] Indeed, we note that the fractional step method [Yanenko, 1971], that is used to split the Wave Action Equation in the WAVEWATCH III model has splitting errors due to different integration time steps in the various phase spaces. Directional spread is particularly sensitive to these errors that typically yield overestimations of the spread [Ardhuin and
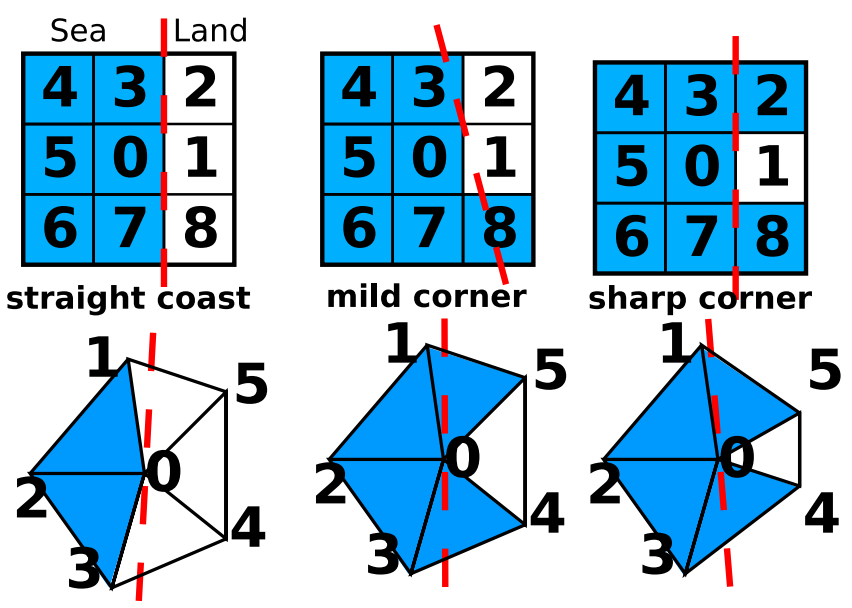

Figure 5. Definition of mean shoreline direction (red dashed line), and type of angle along shoreline for (top) regular grids and (bottom) triangle-based meshes for the model node number 0 . In the case of triangles the model nodes are actually right on the shoreline, whereas for regular grids the shoreline runs between model nodes and the shoreline orientation is defined from the spatial distribution of "wet" (blue) and "dry" (white) neighboring nodes. For triangles, the concept of wet or dry is not applied to the nodes but to the triangles. As a result, for a given node, some directions can be wet, e.g., waves from the northwest in the bottom line, while other are dry, e.g., waves from the east. Reflected components are only added to the dry directions. 


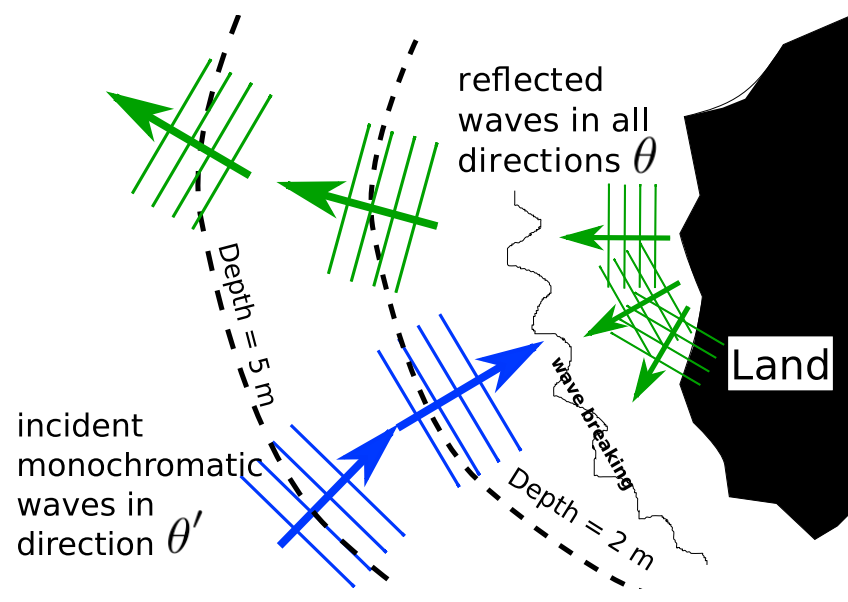

Figure 6. Schematic showing reflection in many directions $\theta$ from a single incident direction $\theta^{\prime}$. Due to refraction and dissipation in the surf zone, the directional distribution of the reflected waves $F_{R}(f, \theta)=R^{2}\left(f, \theta^{\prime}, \theta\right) F\left(f, \theta^{\prime}\right)$ is also a function of the water depth.

Herbers, 2005]. In the stiff case, when, e.g., the refraction term or the source term are far stronger than the advection, as it can be the case in shallow water at steep slopes, the evolving error in splitting can lead to reduction in the order of numerical schemes [Sportisse, 2000] and significant numerical errors [e.g., Roland, 2008, section 7.7]. For this reason, the refraction term is set to zero at the land boundary nodes in the case of triangle-based meshes. For this type of grid we have placed the nodes at a fixed water depth of $5 \mathrm{~m}$ on the shoreline, which is acceptable for our large-scale application, and these nodes are located on the shoreline given by the version 2.0 of the database of Wessel and Smith [1996]. For the U.S. West Coast grid, with our choice of a global time step of $180 \mathrm{~s}$, a spatial advection step of $90 \mathrm{~s}$, and refraction step of $30 \mathrm{~s}$, we did not find a strong sensitivity on the choice of that depth when varied between 1 and $10 \mathrm{~m}$.

[25] For regular grids, which are in practice relatively coarse right at the shoreline, it is relatively difficult to modify the bathymetry of the nearshore nodes to specify the depth without distorting the propagation, and we have thus chosen to use the original bathymetry as it is, so that there is a wide range of depths for the land neighbor nodes, where the reflection term is added.

\section{First Results With Constant Reflection Coefficients}

[26] We first ran a two-way nested model system with two regular grids including a global model at a resolution of $0.5^{\circ}$ and $1 / 6^{\circ}$ model covering a $500 \mathrm{~km}$ wide strip from the Aleutian Islands to Peru, plus Hawaii and French Polynesia. This system was run with $\left(R_{0}^{2}=0.1\right.$, constant $)$ and without coastal reflection, in order to investigate the capability of a regular coarse grid to represent the reflection. Full directional spectra from that system were then used to provide boundary conditions for the two triangle mesh grids around Hawaii (Figure 2) and the U.S. West coast (Figure 3$)$. These models were ran with $\left(R_{0}^{2}=0.1\right.$, constant) and without coastal reflection, for the year 2008. All models were forced by ECMWF wind analyses, which is known to underestimate very high winds but generally give very low random errors [e.g., Ardhuin et al., 2011b]. The forcing also includes sea ice analysis from ECMWF, and small icebergs in the Southern Ocean based on the Ifremer database [Ardhuin et al., 2011c]. These icebergs have very little impact at our coastal validation sites. All results discussed below are from the triangle-based meshes, except for the final application to seismic noise.

[27] A first evaluation of the impact of coastal reflection is given by Table 1 , based on a directional spread over a wide frequency range $(0.04$ to $0.4 \mathrm{~Hz})$, showing that reflection is indeed likely to be an important source of directional spread. We will now discuss the distribution of directional spread as a function of frequency, and generally focus on the lower frequencies, up to $0.16 \mathrm{~Hz}$, for which reflection appears to be relatively more important.

[28] As an illustrative example, we first use the Waimea buoy, number 51201, located $6 \mathrm{~km}$ off the north shore of Oahu, in $200 \mathrm{~m}$ depth. Figure 7 shows measurements and model results using no reflection or a constant coefficient $R_{0}^{2}=0.1$, over the frequency band 0.04 to $0.15 \mathrm{~Hz}$. As stated above, this low reflection coefficient makes almost no difference on the significant wave height (Figure 7c) and on peak or mean periods (not shown). On the contrary, the directional spreads shown in Figure $7 \mathrm{~b}$ exhibit some large effects of the reflection in the wave model, as well as fast variations of the spread which can have large amplitudes, for example from 21 to $25 \mathrm{March}$. These fast variations are partly correlated with the water level measured in Honolulu, with a higher spread near the Honolulu low tide (not shown). These variations are not represented in the wave model, in which we did not include tidal currents nor elevations. These may be due to the motion of the buoy with the tidal currents with a water depth below the buoy that can change by $30 \mathrm{~m}$ over a tidal cycle due to the steep local slope (J. Aucan, personal communication, 2012). This spread modulation may also be associated to a stronger reflection off coral reefs which appear shallower at low tide, an effect similar to the modulation of reflection coefficients observed by Elgar et al. [1994]. However, most of the slow variability in the signal is rather related to the offshore wave conditions, and is well predicted by the model without reflection. Including the reflection in the model generally increases the correlation with the observed time series, and reduces the negative bias in the modeled spreads. It is also clear that the improvement in the first 2 weeks of March, is followed by weak effects and rather poorer results with $R_{0}^{2}=0.1$, suggesting a weaker reflection. This reduced reflection is associated with wave directions oriented more alongshore, except on 26-28 April, when the wave direction is close to the shore normal of $-30^{\circ}$. In that case we also see $R_{0}^{2}=0.1$ leads to an overestimation of the directional spreading, probably because the waves are higher at that time and we know that $R_{0}^{2}$ should decrease when the wave height increases [Elgar et al., 1994; O'Reilly et al., 1999; Guza and O'Reilly, 2001].

[29] Given this sensitivity of directional spread to shoreline reflection, the difficulty is now to specify the reflection coefficients which are expected to depend on the coast geomorphology. Our approach here is to estimate $R_{0}^{2}$ by inverse modeling and then to confront these estimates to 

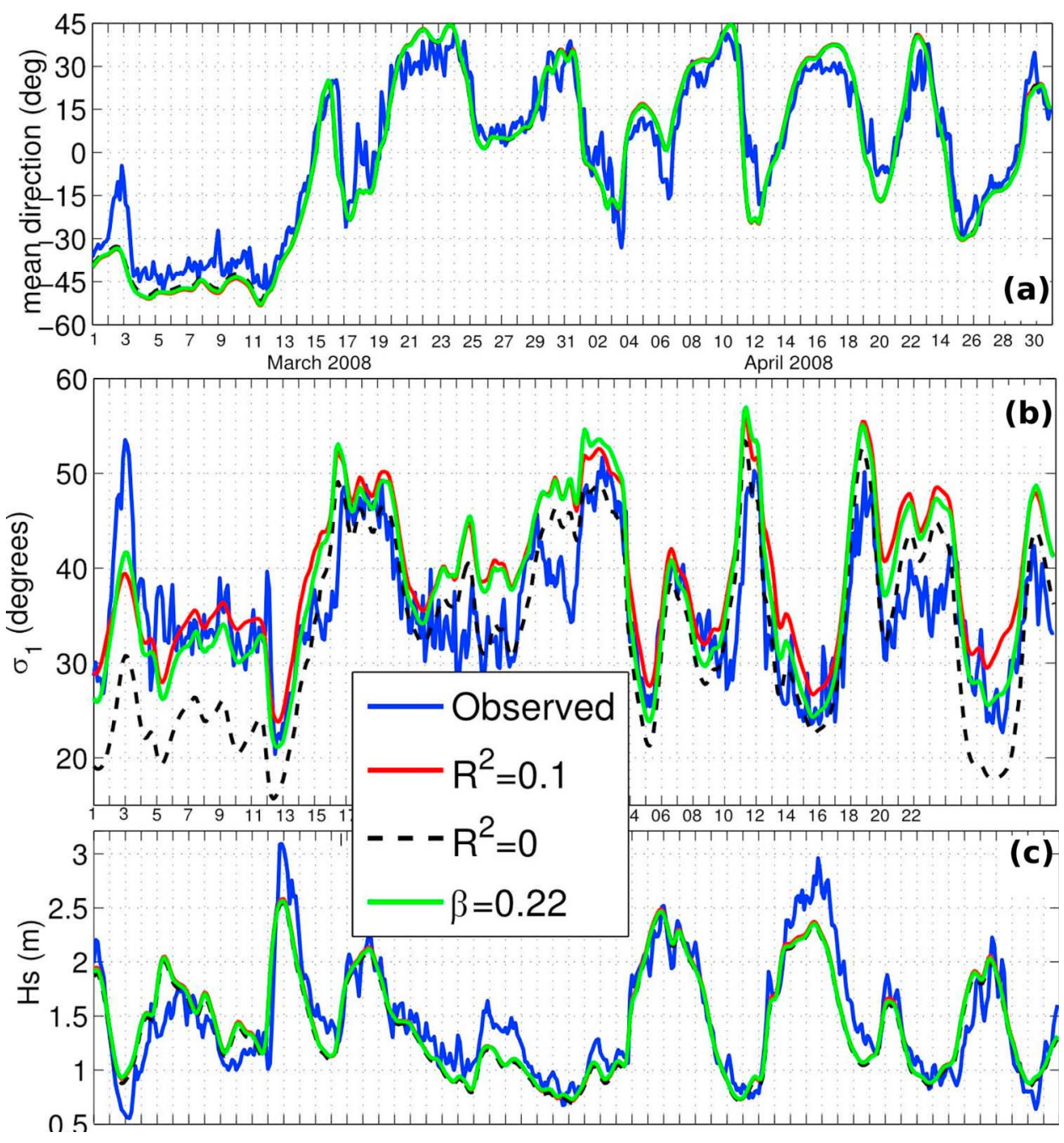

Figure 7. Two months sample of the time series of (a) mean direction, (b) directional spread $\sigma_{1}$, and (c) significant wave height at the buoy 51201 estimated over the frequency band 0.04 to $0.15 \mathrm{~Hz}$ from measured buoy cospectra or from modeled directional moments. The model run " $\mathrm{B} \beta=0.22$ " corresponds to an amplitude-dependent parameterization estimated from a shoreface slope of 0.22 .

actual morphological features. Finally, the shoreline reflection will be verified by independent data using seismic noise records.

[30] Multiple reflections, such as the direction 4 at P1 in Figure $\mathrm{A} 2$, are weak for low values of $R_{0}^{2}$ and may be neglected. In this case, the constant reflection parameterization is linear, and it is possible to combine the two model runs with $R_{0}^{2}=0$ and $R_{0}^{2}=0.1$ in order to reproduce any reflection coefficient. For each buoy we thus search for the reflection coefficient at the shoreline that would give the smallest errors. Figure 8 shows that the model errors vary strongly with frequency, with the most important negative biases found at low frequencies. The low bias at high frequency $(f>0.3 \mathrm{~Hz})$ is also present in deep water (not shown) and is probably not related to shoreline reflection, but rather to a deficiency in the model parameterizations. Further evidence of that deficiency is given by Ardhuin et al. [2010].

[31] In order to focus on coastal reflection effects and avoid errors associated to wind wave generation, dissipation and nonlinear evolution, we will now focus on the frequency range from 0.04 to $0.15 \mathrm{~Hz}$. In that range the model correlation with the data increases rapidly as $R_{0}^{2}$ is increased from 0.02 to 0.1 , but this tends to give high biases for the directional spread. In the following we shall thus define the best fit based on the normalized root-mean-square error (NE), defined as the root-mean-square error, including bias, divided by the root-mean- square measured value. In the case of the Waimea buoy it is given by $R_{0}^{2}$ decreasing from 0.2 at $0.05 \mathrm{~Hz}$, to 0.04 at $0.15 \mathrm{~Hz}$.

[32] By minimizing the NE for the directional spread defined over the frequency range 0.04 to $0.15 \mathrm{~Hz}$, we find the values given in Table 2 for all the buoys considered here. The results indicate that errors can be reduced by almost a factor 2, at the 46212 buoy for example, whereas buoys far from major coastlines, such as 51001 or 46238 , are little sensitive to the modeled shoreline reflection. For the other buoys, we note a strong dependence on buoy location, with fitted reflection coefficients varying from 0.01 at 46235 , to 0.36 at 46013 .

[33] This variability appears to be largely associated with the bottom slope at the shoreface, as expected from the studies by Miche [1951] and others. This slope is very 

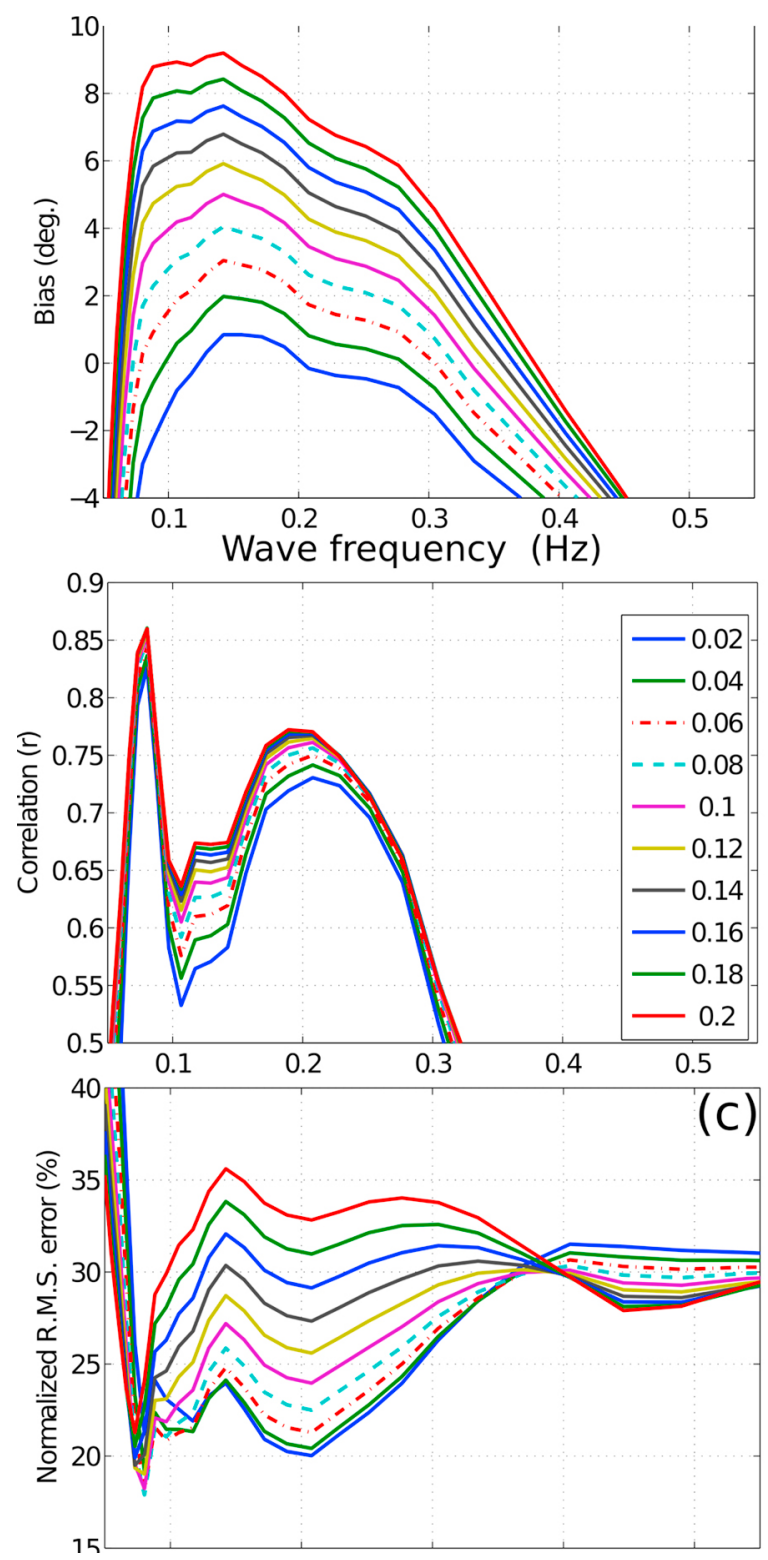

Figure 8. Statistics for modeled directional spread as a function of frequency, and for various values of the shoreline reflection coefficient $R_{0}^{2}$, from 0.02 to 0.2 : (a) bias, (b) correlation, and (c) normalized root-mean-square error.

difficult to estimate from large-scale digital elevation maps or bathymetry, because it is generally poorly surveyed, and because the bottom slopes change rapidly in the ocean to land transition. Here we have used 3" resolution grids generated by the National Geophysical Data Center [2011], lidar data from the NOAA Coastal Services Center (the 1998 post-El Nino surveys of the U.S. West coast, and 1998 lidar surveys for Oahu) as well as the ETOPO2 gridded relief data. In the case of the lidar-derived slopes, reported in Table 2, we have first gridded the data on a 0.0001 degree resolution grid. Slopes were estimated by finite differences, at grid points next to the elevation contour at $1.5 \mathrm{~m}$ above the NAVD88 datum. This level is higher that the mean water level, and thus, for beaches, it generally makes a steeper slope than at lower levels due to the concave beach profile.
Unfortunately, with topographic lidar data that does not penetrate through the water, it is not possible to estimate slopes at lower levels. These slopes were then averaged over a stretch of coast that fills a 60 degree viewing angle from the buoy, around the direction of the nearest land.

[34] Another important pattern in the spreads measured by the buoys, is a strong 12 hourly variability probably associated with tidal elevations that lead to a variation of the shoreface slopes in areas where the slopes vary strongly with the elevation. This variability is particularly strong at buoys 46212 , off Humboldt bay, Northern California, and 46224, off Oceanside, Southern California, which explains the relatively low correlation of the model and observations for these sites.

[35] Although it is difficult to correlate the shoreface slope from high-resolution lidar surveys to coarse ocean bathymetry data, there are some signs, on a global scale, that a shoreline reflection $R_{0}^{2}=0.1$ is improving the wave model in terms of wave height where there are steep underwater slopes. Figure 9 shows that a constant $10 \%$ reflection applied along all shorelines has a largest impact where the ratio of shoreline length to ocean area is largest, namely in large bights, enclosed seas, or between island groups such as in Polynesia. There the mean increase in wave height can reach 5\% (Figure 9a), which would be the expected value for reflection over a straight coast in deep water, without any dissipation (see Appendix A). Such an increase in $H_{s}$ is

Table 2. Estimation of shoreline reflection coefficients and associated model errors on the estimate of the directional spread ${ }^{\mathrm{a}}$

\begin{tabular}{|c|c|c|c|c|c|c|c|}
\hline \multirow[b]{2}{*}{ Buoy } & \multirow[b]{2}{*}{$\begin{array}{c}R_{0}^{2} \\
\text { Fitted }\end{array}$} & \multicolumn{3}{|c|}{ NE (\%) } & \multirow[b]{2}{*}{$\begin{array}{c}\beta_{0} \\
\text { Fitted }\end{array}$} & \multirow[b]{2}{*}{$\begin{array}{c}\beta \\
\text { Lidar }\end{array}$} & \multirow[b]{2}{*}{$\mathrm{NE} \beta=\beta_{0}(\%)$} \\
\hline & & $\begin{array}{c}R_{0}^{2} \\
\text { Fitted }\end{array}$ & $R_{0}^{2}=0$ & $R_{0}^{2}=0.1$ & & & \\
\hline 51001 & 0.40 & 11.6 & 11.8 & 11.7 & 0.40 & & 11.2 \\
\hline 51201 & 0.06 & 18.1 & 21.4 & 19.5 & 0.19 & 0.21 & 18.8 \\
\hline 51202 & 0.00 & 20.1 & 20.1 & 20.5 & 0.16 & 0.17 & 20.0 \\
\hline 46041 & 0.07 & 21.3 & 22.7 & 21.5 & 0.23 & & 20.7 \\
\hline 46211 & 0.21 & 16.7 & 30.1 & 20.5 & 0.31 & 0.08 & 19.1 \\
\hline 46050 & 0.16 & 21.5 & 31.8 & 23.0 & 0.33 & 0.09 & 20.8 \\
\hline 46229 & 0.13 & 14.8 & 22.5 & 15.3 & 0.30 & 0.11 & 15.7 \\
\hline 46212 & 0.08 & 14.8 & 34.7 & 16.7 & 0.23 & & 15.6 \\
\hline 46022 & 0.06 & 24.7 & 26.6 & 25.2 & 0.28 & & 23.2 \\
\hline 46214 & 0.25 & 14.4 & 19.2 & 16.1 & 0.35 & 0.31 & 15.8 \\
\hline 46013 & 0.36 & 15.7 & 33.0 & 24.6 & 0.40 & 0.21 & 19.2 \\
\hline 46236 & 0.08 & 14.9 & 29.1 & 16.1 & 0.22 & 0.11 & 15.3 \\
\hline 46042 & 0.32 & 16.8 & 23.9 & 20.0 & 0.36 & 0.28 & 18.3 \\
\hline 46028 & 0.18 & 21.3 & 23.5 & 21.7 & 0.31 & 0.17 & 21.5 \\
\hline 46011 & 0.30 & 16.4 & 28.2 & 21.4 & 0.38 & 0.29 & 17.5 \\
\hline 46219 & 0.11 & 12.8 & 13.0 & 12.8 & 0.26 & & 12.9 \\
\hline 46234 & 0.07 & 16.9 & 32.4 & 18.3 & 0.10 & 0.08 & 16.8 \\
\hline 46221 & 0.16 & 15.7 & 24.3 & 16.9 & 0.20 & 0.15 & 14.2 \\
\hline 46223 & 0.15 & 17.4 & 26.2 & 18.3 & 0.19 & 0.29 & 17.3 \\
\hline 46224 & 0.11 & 15.3 & 20.7 & 15.3 & 0.17 & 0.15 & 14.5 \\
\hline 46242 & 0.04 & 14.6 & 25.1 & 29.0 & 0.07 & 0.05 & 14.1 \\
\hline 46225 & 0.04 & 14.6 & 15.8 & 16.3 & 0.13 & 0.15 & 13.7 \\
\hline 46235 & 0.01 & 14.1 & 14.8 & 45.0 & 0.05 & 0.09 & 15.1 \\
\hline 46232 & 0.05 & 12.9 & 13.5 & 13.3 & 0.15 & & 12.7 \\
\hline 46238 & 0.12 & 13.2 & 14.2 & 13.2 & 0.20 & & 13.3 \\
\hline
\end{tabular}

${ }^{\mathrm{a}}$ Normalized root-mean-square errors (NE) are given for the best-fit constant reflection as well as zero or 0.1 energy reflection coefficients. All buoy spread estimates were computed from 3 hourly averaged directional moments $a_{1}$ and $b_{1}$ averaged over the frequency band 0.04 to $0.13 \mathrm{~Hz}$. Only conditions for which the mean wave directions (from) is within $90^{\circ}$ of the normal to the nearest coast are considered, and the full year 2008 is used. Errors with an amplitude-dependent reflection that is a function of the shoreline slope $\beta$ (see section 4) are also give, together with the value $\beta_{0}$ of the shoreline slope that gives the smallest errors. 

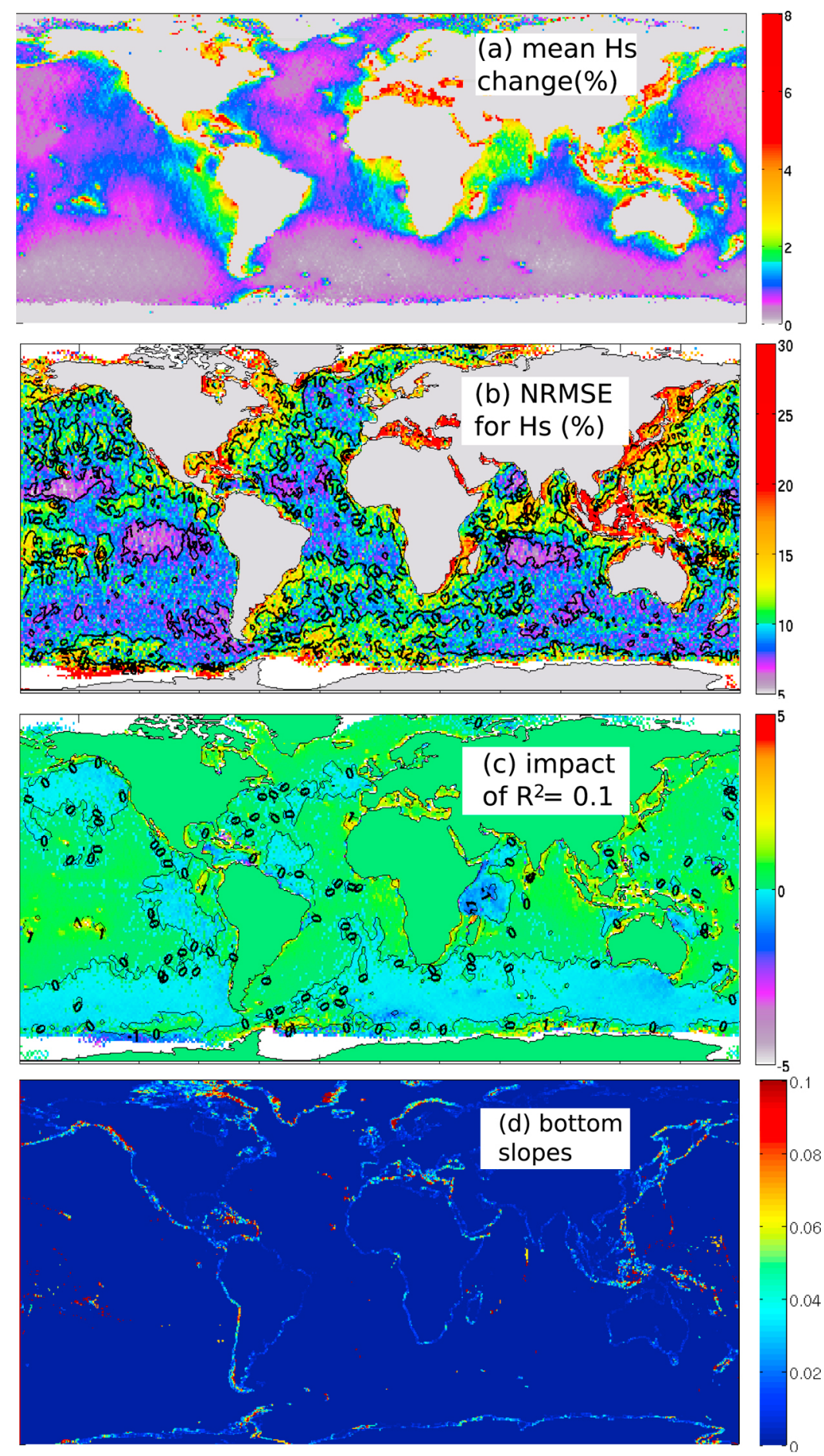

Figure 9. Impact of reflection, global-scale errors, and bottom slopes. (a) Average of the relative increase in wave height, from 0 to $8 \%$, when a constant $10 \%$ energy reflection is used along all coastlines. (b) Wave model normalized root-mean-square error (NE) for the significant wave height against all satellite altimeters for the year 2008; this model configuration and further validation is discussed in Ardhuin et al. [2011c]. (c) Map of the difference in NE between the run without and with reflection. Positive values (yellow) correspond to locations where the model results with reflection are better. (d) Mean bottom slopes over the grid points adjacent to land, based on the ETOPO2 data set.

significant compared to typical wave model errors, and it is possible that model errors, when compared to altimeter data (Figure 9b) are partly associated to errors in coastal reflection. The normalized error are reduced by typically 2 points, from about $15 \%$ to $13 \%$ along the Norwegian coast, where $R_{0}^{2}$ is expected to be important, of the order of 0.1 or more, while the error is increased along the northern Brazilian coast where the shallow estuaries should give very little 


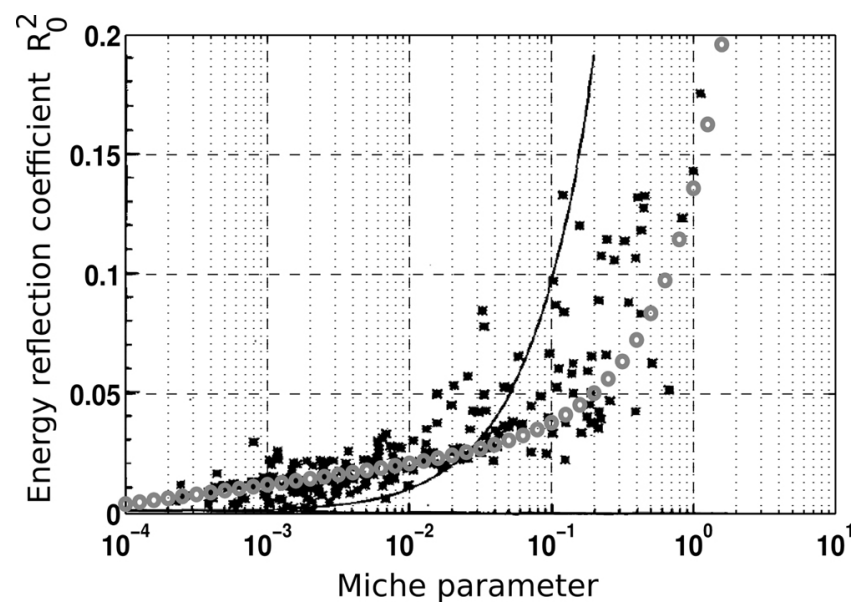

Figure 10. Energy reflection coefficient as a function of the Miche parameter. The black stars show the measurements by Elgar et al. [1994] and the open circles shows the parametric fit given by equation (13). The solid line is $R_{0}^{2}=$ Mi.

reflection, typically $R_{0}^{2}<0.02$. There are, however, many counterexamples such as the long stretches of beaches in northwest Australia or the low-lying shorelines of the northern Gulf of Mexico that are not expected to cause much reflection, but where the model results are improved. These improvements are due to the reduction of the negative biases which can have many other sources, including a general tendency to underestimate wave heights at short fetches [Ardhuin et al., 2010], or the fact that these simulations did not take into account currents [Rascle et al., 2008].

\section{Amplitude-Varying Reflection}

\subsection{Parameterization}

[36] Beyond the spatial variation of the reflection coefficient, which should be linked to the shoreface slope, there is also a clear dependence of reflection on wave periods. Elgar et al. [1994] explored the relation of the measured reflection coefficient for wind seas and swell with the Miche parameter

$$
\mathrm{Mi}=\frac{16(\tan \beta)^{5}}{(2 \pi)^{5} H_{\infty}^{2} f^{4}},
$$

with $f$ the wave frequency, $\beta$ the shoreface slope, and $H_{\infty}$ the wave height in deep water. Following Miche [1951] who studied monochromatic waves, Elgar et al. [1994] found that $R_{0}^{2}=\mathrm{Mi}$ is an acceptable approximation for random waves on a natural beach. Now working with random waves, we shall use the mean frequency $f_{m 0,1}$ instead of $f$ in the definition of the Miche parameter.

[37] Looking at the data of Elgar et al. [1994] in more detail, Figure 10 suggest that energy reflection coefficient is well approximated by

$$
R_{0}^{2}=0.007 \log _{10}(\mathrm{Mi}+4.5)+0.15 \mathrm{Mi},
$$

which is shown by the red circles, and which we have used in the wave model.
[38] In order to obtain a reflection coefficient for random waves, we have redefined the Miche number (12) by replacing $H_{\infty}$ with the significant wave height outside of the surf zone, and $f$ with the mean frequency $f_{m 0,1}$ which is expected to be close to the "centroid frequency" used in the data analysis by Elgar et al. [1994]. We have further generalized equation (13) to obtain a frequency-dependent reflection

$$
R_{0}^{2}(f)=\left[0.007 \log _{10}(\mathrm{Mi}+4.5)+0.15 \mathrm{Mi}\right]\left[\max \left\{1, \frac{f_{m 0,1}}{1.3 f}\right\}\right]^{m} .
$$

With an exponent $m>1$, the reflection of low-frequency components is amplified, namely for $1.3 F<f_{m 0,1}$. This frequency dependence is critical for reproducing the broad directional spectra just below the peak frequency, and the best results are obtained with $m=3$. It is possible that $m=3$ gives an overamplification of the reflection at low frequencies, correcting for lack of second-order spectral terms in the model [Krogstad and Trulsen, 2010]. Still, this dependence on frequency is not too far from the value $m=2.58$ reported by Sutherland and O'Donoghue [1998] for small reflections. These authors also have a reflection coefficient that is proportional to $1 / H_{s}^{2}$. We have also attempted to include a dependence on the incidence direction but this did not improve the model results.

[39] Based on equation (14) we have combined the calculations with $R_{0}^{2}=0$ and $R_{0}^{2}=0.1$ as a function of the Miche number $\mathrm{Mi}$, in order to estimate the bottom slope $\beta_{0}$ that gave the smallest error for each buoy, in terms of modeled directional spread. These slopes $\beta_{0}$ are listed in Table 2 .

[40] Contrary to the fitted constant reflection coefficients, estimates of $\beta_{0}$ vary only weakly with the frequency band selected for analysis. With the exception of buoy 46211 , 46050 and 46229 , we note that these fitted slopes are comparable with locally averaged shoreface slopes estimated from topographic lidar data, as listed in Table 2. The $\beta_{0}$ slopes are also weakly correlated $(r=0.50)$ with the underwater nearshore slopes in the 3 " bathymetric gridded data. However, in that latter case we found a factor of 2 between the bathymetry data and our best-fit slope, as shown in Figure 11. It is generally expected that the slope of the shoreface is larger than the nearby ocean bottom slope [e.g., Stockdon et al., 2006], and that effect is probably an important source of the differences found here.

[41] The most conspicuous outliers are the northwest buoys $46041,46211,46050$ and 46229, which give much higher directional spreads than can be accounted for by shoreline reflection based on the available topographic data. It is possible that tidal currents may be the source of some of that directional spread, through refraction and scattering [e.g., Fabrikant and Raevsky, 1994]. We found a similar underestimation at WMO buoy number 62069, located off the French coast, where we have verified the refraction effects of currents on the waves.

\subsection{Modeled Directional Spreads}

[42] Based on these results we implemented a spatially varying shoreface slope in the numerical model, taken as twice the nearest shoreline slope estimate from the 3 " bathymetry grids (the U.S. west coast lidar coverage is 


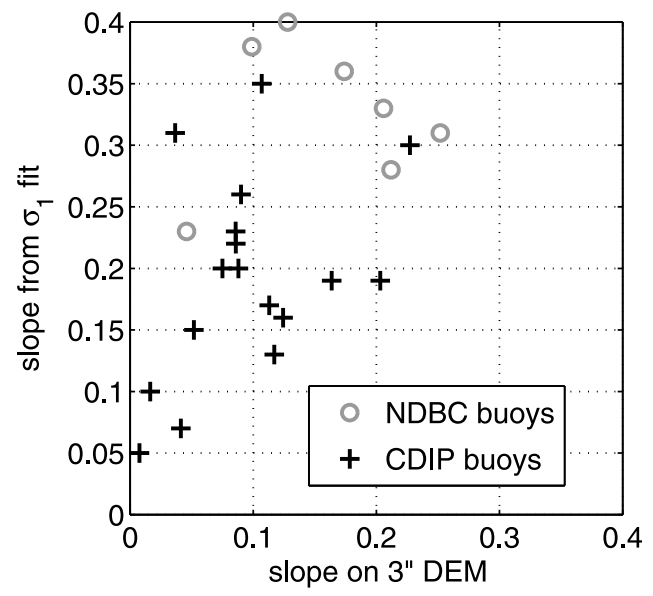

Figure 11. Shoreface slopes that give the lowest errors compared to nearshore bottom slopes estimated from pixels adjacent to the land-sea boundary, on the ocean side, in $3^{\prime \prime}$ resolution digital elevation models.

fairly extensive but not complete). In general, this spatially varying shoreline slope gives the most accurate results but the model result is very sensitive to the shoreface slope. Figure 12 illustrates the difference between buoys 46214, located offshore of San Francisco, and the nearby buoy 46236, located in Monterey Bay. Both buoys are exposed to the same swell fields arriving from the Pacific. Buoy 46236 is particularly sensitive to shoreline reflection. This is probably due to the location of the buoy, inside the bay, which receives reflected components from all around it. This large effect of reflections in bays is consistent with the results shown in Figure 9a for the global scales, similar to the larger energy at the focal point of a parabolic mirror.

[43] Figure 12a shows several storm events with wave heights ranging from 1 to $6 \mathrm{~m}$. For the directional spread at 46214 , the alongshore-varying slope estimated from twice the value in the 3 " digital elevation models (DEMs) is equivalent to a constant $\beta=0.2$ slope (Figure $12 \mathrm{~b}$ ). With such a slope, the observed directional spreads at are weakly underestimated by the model at 46214. However, at buoy 46236 in Monterey bay, this large slope leads to a strong overestimation of the spread and larger errors than any other model run (Figure 12c). The modeled spread are particularly large whenever the wave height becomes very small or the mean period becomes very large. Using a local shoreface slope based on the DEMs gives a much better model results. Model results are thus very sensitive to the shoreline slope, which, if not well estimated, may produce errors larger than those obtained with a constant shoreline reflection.

[44] From the last column of Table 2, it may seem that the improvements brought by a parameterization with the shoreface slope brings only a marginal improvement, if any, to the estimates of the directional spreads. This rather misleading impression comes from the frequency integration. In fact, if one considers different frequency subranges, the best fit for $R_{0}^{2}$ generally exhibits a larger variability than the best fit for $\beta_{0}$. Taking the case of buoy 46229 off the Oregon coast, the lowest error is obtained with $R_{0}^{2}=0.12$ for frequencies in the range $0.04-0.24 \mathrm{~Hz}$, and it increases to

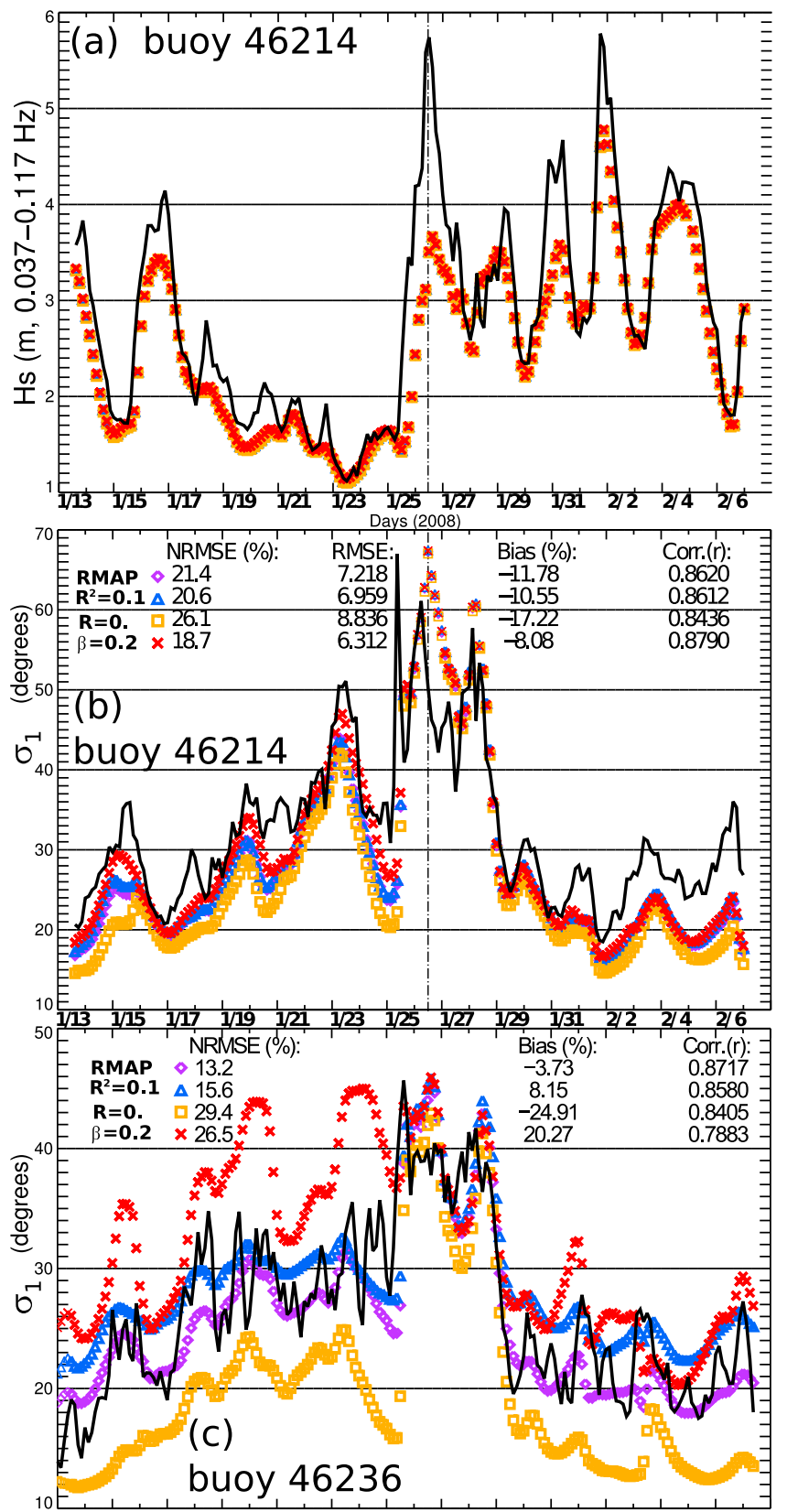

Figure 12. Model results with different reflection parameterizations for 30 days in 2008 based on the unstructured U.S. West Coast grid. (a) Significant wave height over the frequency range 0.037 to $0.11 \mathrm{~Hz}$ and directional spread at buoys (b) 46214 and (c) 46236 over the same frequency range. The observations are shown with the solid line, and the different model results with different symbols. Namely, the model based on the 3 " DEM slopes, multiplied by 2 , is shown with purple diamonds, whereas the model with a constant 0.1 reflection coefficient is in blue and the model without reflection is shown with orange squares. A constant beach slope of 0.2 gives the results shown with red crosses. The narrower frequency range used here was designed to remove large directional spreads when a wind sea and swell from different directions are present at the same time. 

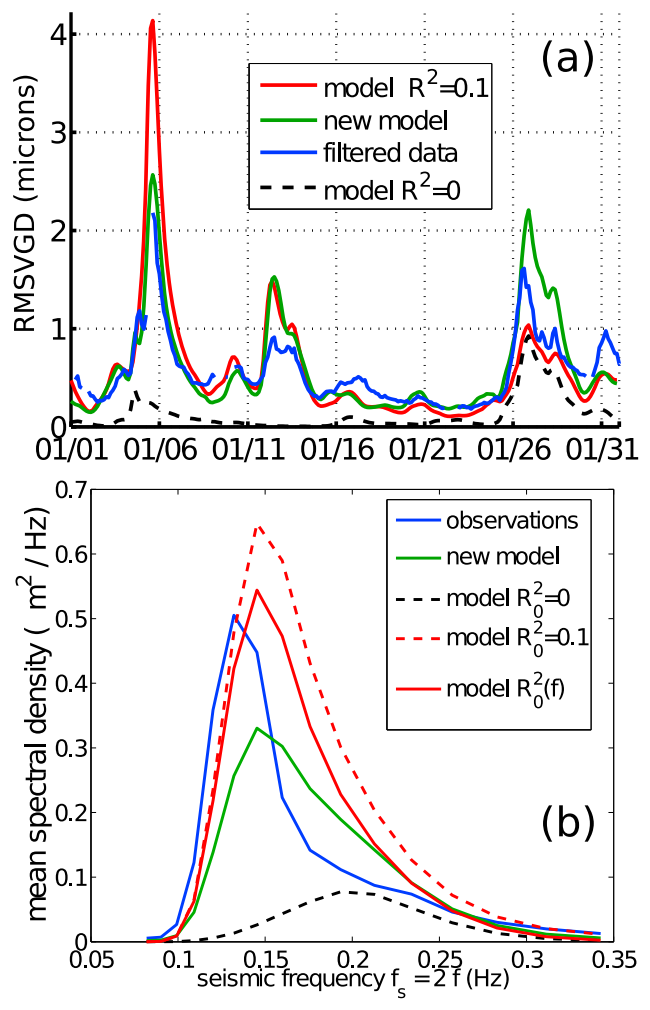

Figure 13. Modeled seismic noise at the Berkeley seismic station (see Figure 3) based on the same seismic propagation model used by Ardhuin et al. [2011a], with a quality factor $Q=300$. (a) Time series of the root-mean-square vertical ground displacement modeled and recorded at the Berkeley seismic station, for the month of January 2008. (b) Frequency spectra of the seismic noise averaged over the entire year 2008.

$R_{0}^{2}=0.18$ for $0.04-0.09 \mathrm{~Hz}$. For this low-frequency range, the correlation is reduced from 0.81 to 0.47 .

[45] In contrast, when using a parameterization based on the shoreline slope, the estimated value of $\beta_{0}$ is 0.09 and 0.08 for the two frequency ranges, and the correlation remains as high as 0.80 for both.

\subsection{Modeled Seismic Noise}

[46] Because shoreline reflection was introduced in WAVEWATCH III for the purpose of modeling the secondorder wave spectrum and the associated sources of seismic or atmospheric noise, it is important to verify the influence of the new reflection parameterization on this parameters. Further, the spread may be sensitive to other phenomena beyond wave reflection at the shoreline, and it is interesting to also investigate these other phenomena that are associated to the second-order wave spectrum at very small wave numbers, which is much more sensitive to reflection, due to the directional integral $I(f)$ given by equation (2). The local source of seismic noise is proportional to $I(f)$, so that the largest sources are associated with opposite swell and wind sea at the same frequency, or coastal reflection [Ardhuin et al., 2011a; Schimmel et al., 2011]. In the case of the spectra shown in Figure 1, coastal reflection increases the spread at the peak frequency by $23 \%$, whereas $I\left(f_{p}\right)$ is multiplied by 60 .
[47] Because the sources of noise recorded at a seismic station can have a very large spatial extent, we now use our global model configuration with a rectangular grid. In this model configuration, the shoreline slope is taken to be twice the slope estimated from the ETOPO2 and the coastal 3" DEMs, and the reflection is estimated using equation (14). The goal of this simulation is to provide an independent verification of the influence of coastal reflection on the directional wave spectra.

[48] From the wave spectral parameters $E(f)$ and $I(f)$, the source of seismic Rayleigh waves is given by [LonguetHiggins, 1950; Hasselmann, 1963]

$$
S_{D F}\left(f_{s}\right) \simeq \rho_{w}^{2} g^{2} \frac{4 \pi^{2} f_{s}^{2} \widetilde{C}}{\rho_{s}^{2} \beta_{s}^{5}} E^{2}(f) I(f),
$$

where $\rho_{w}=1000 \mathrm{~kg} \mathrm{~m}^{-3}$ and $\rho_{s}=2500 \mathrm{~kg} \mathrm{~m}^{-3}$ are the water and crust density, and $\beta_{s}=3000 \mathrm{~m} \mathrm{~s}^{-1}$ is the crust shear wave velocity, also assumed constant. A missing $2 \pi$ factor in equation (5) of Ardhuin et al. [2011a] has been corrected here, it was included in their calculations.

[49] The local conversion from ocean waves to seismic Rayleigh waves is a function of the ratio of sound wavelength and water depth, represented by a nondimensional coefficient $\widetilde{C}$ [Longuet-Higgins, 1950; Ardhuin et al., 2010].

[50] Finally, the seismic noise power spectrum $F_{\delta}$ recorded on the vertical component at a station of longitude $\lambda$ and latitude $\phi$ on the Earth's surface is given by the directional wave spectra over the ocean at all positions $\left(\lambda^{\prime}, \phi^{\prime}\right)$ through the source $S_{D F}\left(f_{s}\right)$. With $\Delta$ the spherical distance between source and station, and $R_{E}$ the Earth radius, it is

$$
F_{\delta}\left(\lambda, \phi, f_{s}\right)=\int_{\Omega} \frac{S_{D F}\left(\lambda^{\prime}, \phi^{\prime}, f_{s}\right) P}{R_{E} \sin \Delta} \mathrm{e}^{-2 \pi f_{s} \Delta R_{E} /(U Q)} \mathrm{d} A,
$$

where $\mathrm{d} A=R_{E}^{2} \cos \phi^{\prime} \mathrm{d} \lambda^{\prime} \mathrm{d} \phi^{\prime}$ is the elementary area of the ocean surface $\Omega$, and $U \simeq 1.8 \mathrm{~km} \mathrm{~s}^{-1}$, the group speed of the Rayleigh waves considered here. $P$ is an empirical correction factor for three-dimensional propagation effects. When $P=1$ as in Ardhuin et al. [2011a], the propagation of the seismic (Rayleigh) waves correspond to a vertically symmetric earth model. Seismic wave attenuation is represented by the quality factor $Q$.

[51] The main difficulty in the modeling of seismic noise, beyond the parameterization of shoreline reflection, is the estimation $Q$ and $P$ that are not well known. In order to facilitate a comparison with the earlier results reported in Ardhuin et al. [2011a], we have kept the constant seismic damping $Q$ which is generally consistent with known oceanic crust propagation, but many studies suggest that $Q$ is a function of the frequency. We have adjusted $P$ to maximize the fit between model and observations.

[52] Here we use data from the Berkeley seismic station, located east of San Francisco, just across the San Francisco Bay (see Figure 3) for which the noise sources are expected to be mostly located are near the shelf break between buoys 46022 and 46028 [Ardhuin et al., 2012]. For these relatively short distances, the denominator in equation (16) is the distance between the source and the BKS station, so that we expect the effect of coastal reflection will be dominated the steepest segments of the shoreline that are also nearest to San Francisco. 


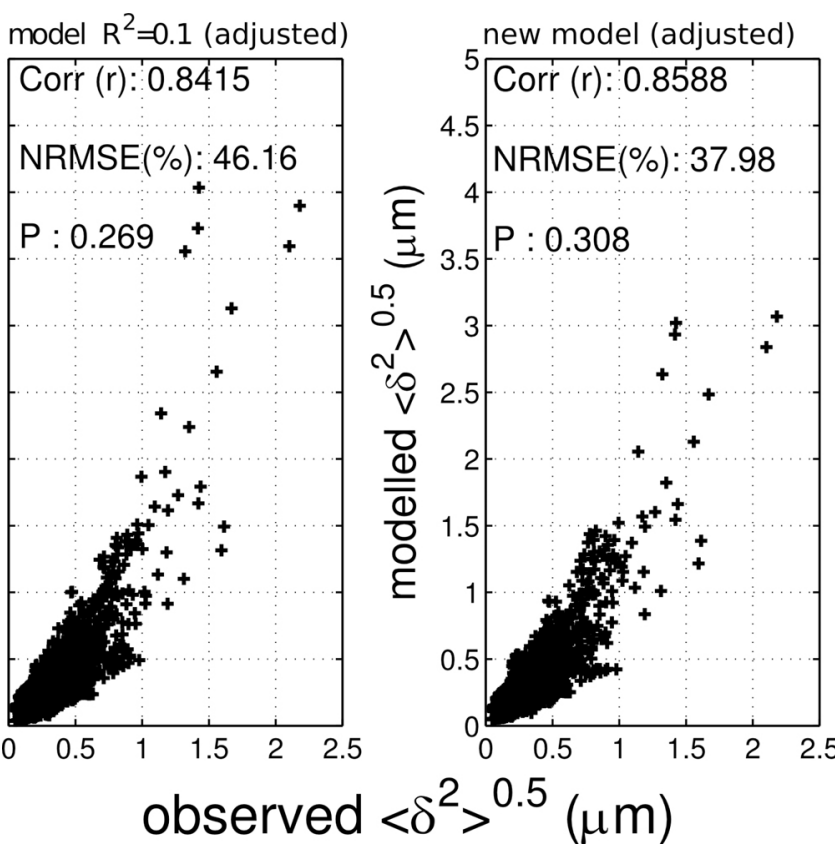

Figure 14. Scatterplots of modeled versus observed rootmean-square vertical ground displacement $\delta$ for the model with a (left) constant reflection coefficient and (right) coefficient defined from the spatial varying slope, based on equation (14). The values of $P$ indicated here are the bias correction in equation (16), that is expected to account for 3 -D seismic propagation effects. There is one symbol for each $3 \mathrm{~h}$ record of the year 2008 .

[53] Figure 13 illustrates the impact of the reflection, and the behavior of the different reflection parameterizations. Given the empirical factors $Q$ and $P$, the important aspects of the comparison between data and model is not in the absolute error between the two, but rather in their relative variation and correlation. With this in mind, the first clear conclusion is that it impossible to reproduce the variability of the seismic noise without any wave reflection at the shoreline, as shown by the dashed line in Figure 13a. This is consistent with many previous analyses of seismic noise recorded along the U.S. West coast [e.g., Bromirski et al., 1999; Ardhuin et al., 2011a]. The use of a constant reflection coefficient $R_{0}^{2}=0.1$ gives a reasonable reproduction of the time series (see also Ardhuin et al. [2011a] for the full year), but it produces a factor 2 overestimation of the measured value on 6 January, and a $30 \%$ underestimation on 26 January.

[54] This relative dynamic range, larger that that of the observations, is unchanged when one tries to adjust the coefficient $R_{0}^{2}$ as a function of frequency only. Here we have used, $R_{0}^{2}(f)=0.14-0.8 f$, which was previously adjusted by Ardhuin et al. [2011a]. This frequency dependence reduces part of the high-frequency overestimation shown in Figure 13b, and mimics the frequency dependence of the reflection coefficient defined from the shoreface slopes (red line). However, all these spectra are still fairly different from the observed seismic spectrum. This difference can be removed by using a plausible variation of $Q$ with $f$ (not shown), from about 320 to 100 in the range of frequencies used here. This decrease in $Q$ would maximize the model- data correlation at each frequency [see Ardhuin et al., 2011a, Figure 8d]. This relatively poor knowledge of $Q$ makes it difficult to conclude on the realism of the frequency dependence in our parameterization of $R_{0}^{2}$ based on equation (14). The lower scatter of the noise obtained throughout the year with this parameterization, as shown in Figure 14, is an indication that the amplitude dependence is realistic, with a smaller value of $R_{0}^{2}$ for smaller wave heights, consistent with all observations [Guza and O'Reilly, 2001; Elgar et al., 1994].

\section{Conclusions and Perspectives}

[55] Following O'Reilly et al. [1999] and Ardhuin et al. [2011a], we have confirmed that coastal reflection is needed to reproduce the relatively broad directional spectra that are recorded by buoys off the California coast, and around the island of Oahu. The analysis of directional data from 22 different buoys indicates that this reflection is strongest offshore of steep shorelines, and that the model errors on the directional spread are well reduced when using a parameterization of shoreline reflection that is a function of the slope at the shoreface and the wave amplitude.

[56] However, the model is very sensitive to the shoreface slope. This sensitivity is illustrated by the fast temporal variability of directional spread at some buoys, likely related to variations in the mean water level with the tides [see also Elgar et al., 1994]. As a result, an accurate estimate of the shoreface slope is needed. In the absence of available database on shoreline slopes, we started building our own, giving the preliminary results shown here.

[57] At present, it is still unclear that a representative shoreline slope can be defined from a long stretch of heterogeneous coast, for use in a relatively coarse wave model. Our results suggest that such a parameterization may still be applied at global scales with beneficial impacts on the estimation of seismic noise sources. An important work remains to be done for correcting and validating the slopes estimated from coarse 2 to $4 \mathrm{~km}$ resolution bathymetry grids such as ETOPO2 and ETOPO1. We found that effective slopes, derived from model errors against buoy data, are relatively well correlated with shoreline slopes estimated from lidar surveys with horizontal resolutions of a few meters. Using these surveys will be very useful to refine the estimates of the shoreline slope from the coarse grid data. In this process the comparison of recorded and modeled seismic noise will be an important validation tool for the refinement of this global shoreline slope database. There is also a need for more recordings of bottom pressure at frequencies above $0.2 \mathrm{~Hz}$ and water depths larger than $15 \mathrm{~m}$, as these measurements are dominated by the second-order wave spectrum, which is very sensitive to the presence of reflected wave components, as demonstrated by Herbers and Guza [1991, 1994].

\section{Appendix A: Simple Numerical Tests of the Reflection}

[58] Here we discuss simplified simulations with all source terms set to zero, except for reflection. These propagationonly simulations are designed to show the details of the numerical implementation of the reflection term. In order to 

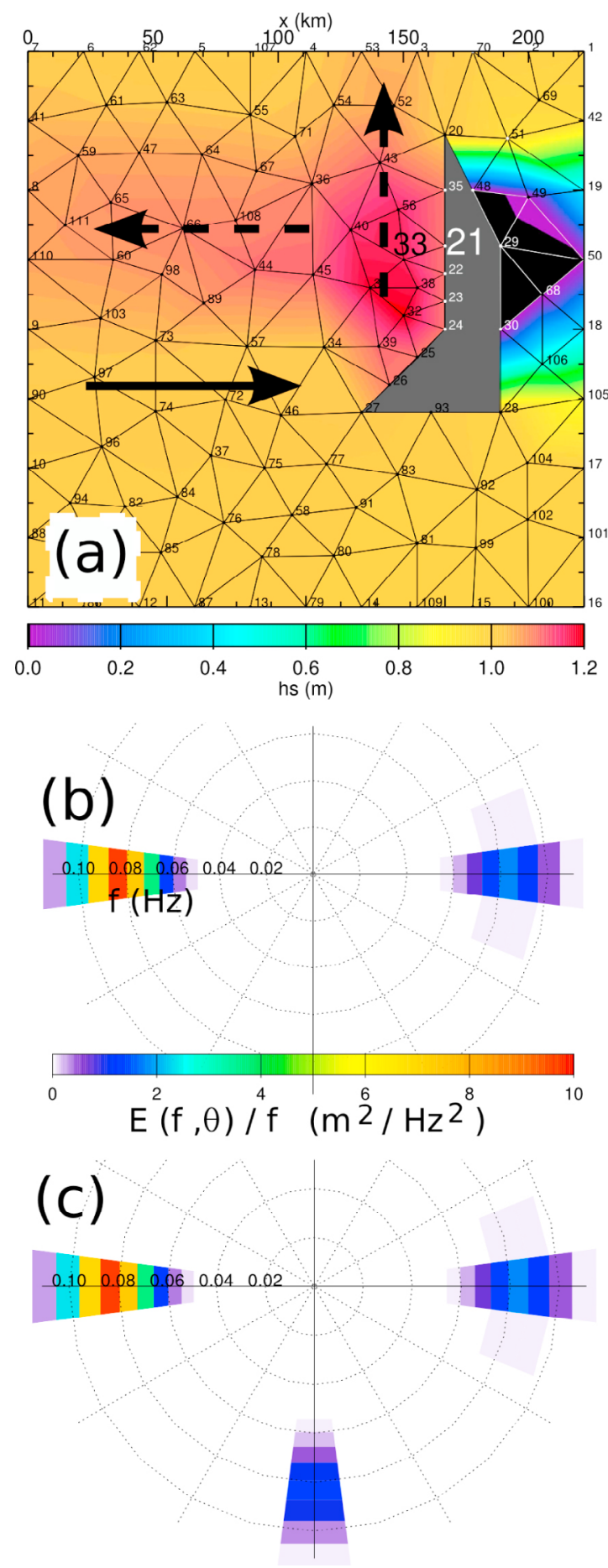

Figure A1. Academic test for reflection on unstructured grids. (a) Mesh and wave heights resulting from an incident unidirectional wavefield, and constant near-specular $(m=100)$ reflection $R_{0}^{2}=0.2$ on a polygon-shaped island (grey area). The incident direction, from west, is indicated with the solid arrow, and the two specular directions $\theta_{r}$ for the two segments of the island exposed to the incoming waves. Each node is identified by a number. (b) Directional wave spectrum on the island boundary (at node number 21). (c) Spectrum at a neighboring node, number 33, in the domain. Please note that energies are shown in the direction from which it is arriving.
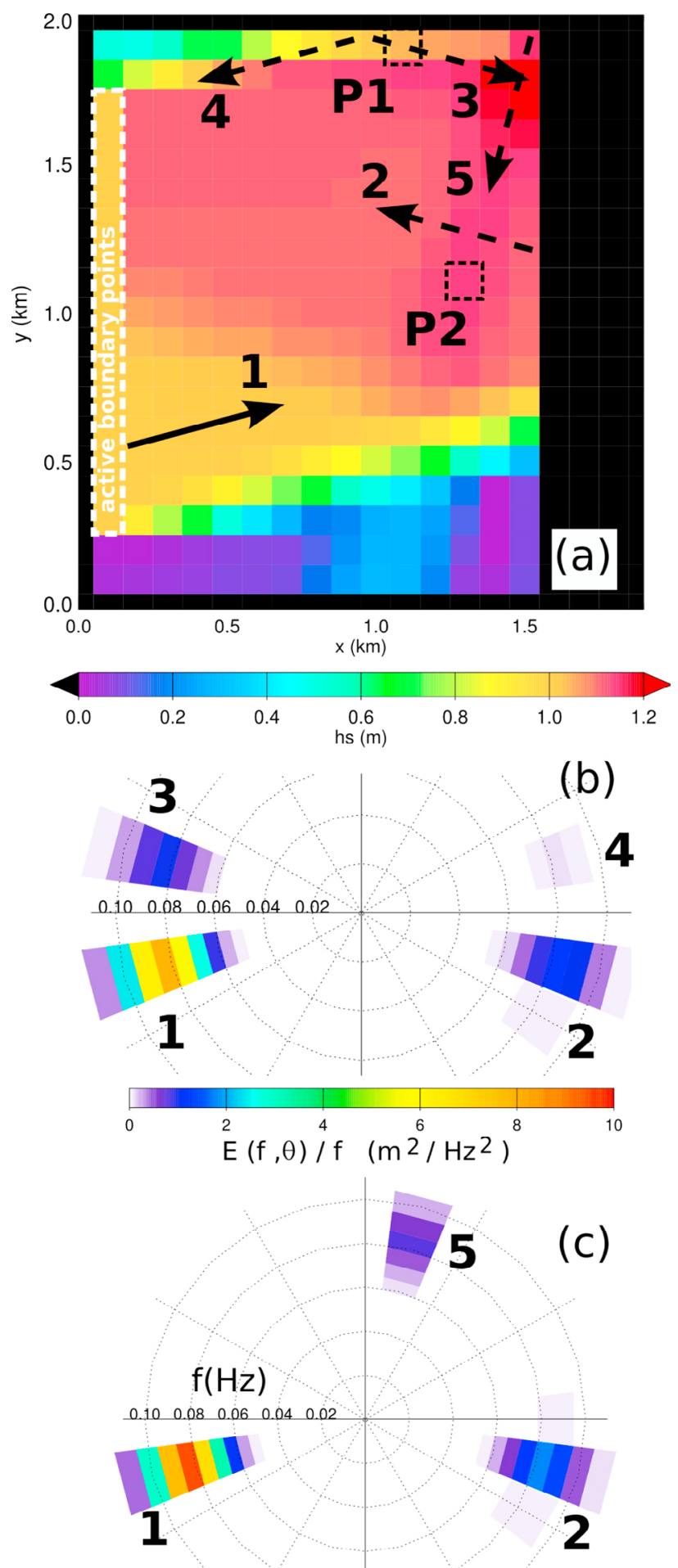

Figure A2. Academic test for reflection on a regular grid: case of a rectangular domain. (a) Wave heights resulting from an incident unidirectional wavefield and constant near-specular $(m=100)$ reflection $R_{0}^{2}=0.2$. The incident direction 1 , from $255^{\circ}$, is indicated with the solid arrow, and various specular directions $\theta_{r}$ are indicated with dashed arrows. In the case of direction 5 , it is due to the definition of the local shore normal $\theta_{n}=45^{\circ}$ for the grid point in the upper left corner, where as $\theta_{n}=90^{\circ}$ or 0 for the straight parts of the boundary. (b) Directional wave spectrum at point P1 and (c) spectrum at point P2. 

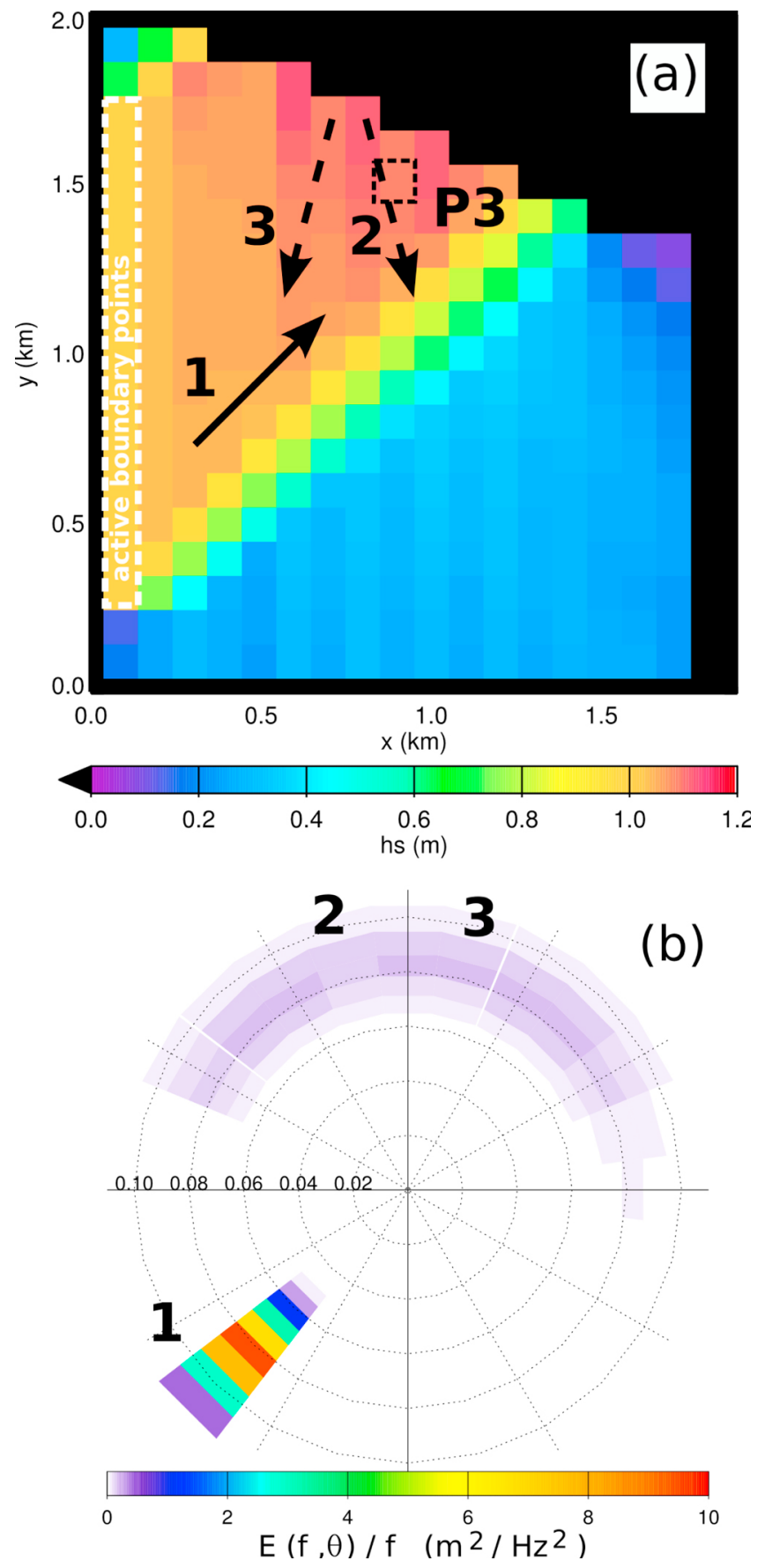

Figure A3. Academic test for reflection on a regular grid: case of a domain with an oblique boundary. (a) Wave heights resulting from an incident unidirectional wavefield and constant diffuse $(m=1)$ reflection $R_{0}^{2}=0.2$. The incident direction 1 , from $225^{\circ}$, is indicated with the solid arrow, and various specular directions $\theta_{r}$ are indicated with dashed arrows. (b) Directional wave spectrum at point P3.

facilitate the understanding of the model results, we first use a nearly specular reflection $(m=100$ in equation (10)) which makes it easier to distinguish the different directions.

[59] The most simple numerical configuration is given by the triangular meshes for which the spectrum is directly imposed on the boundary nodes and the local shoreline direction, which is used to define the specular direction $\theta_{r}$ is simply given by the average direction of the two boundary segments that are joined at each boundary node. An Example of this setting is given in Figure A1. The actual reflected energies are within $0.1 \%$ of the prescribed reflection coefficients.

[60] The model verification is more complex in the case of regular grids, first of all because of the discrete estimation of the shore-normal directions. Figure A2 shown an example map of wave heights. In that case the boundary condition is imposed only for the grid points inside the white dashed area, on the left hand side, with a slightly oblique unidirectional wave spectrum. This map reveals a particular behavior in the upper right corner, which is due to our local definition of the shore-normal direction. Indeed we have only one shoreline direction for each shore neighbor node, and in the corner it is an oblique direction. This corner is sending a beam of wave energy in direction 5 . This effect depends on the resolution as it would be confined to a much smaller length alongshore if the grid had a finer resolution. That effect could be thought as a defect in our parameterization. However, in the case of a naturally irregular shoreline, it provides a smoother transition for the shore-normal directions, from $\theta_{n}=0$ to $\theta_{n}=90^{\circ}$.

[61] Also, this discrete energy beam is strongly blurred with our use of a more diffuse reflection with $m=1$ in this kind of corner. When applying our scheme with a diffuse reflection, as used in the paper, the effective reflection coefficient can be slightly reduced. Figure A3 shows one case in which the directional spectrum only has $17 \%$ of energy in reflected directions, compared to a nominal $20 \%$. This limitation appears acceptable in view of the simplicity of the reflection parameterization used here. In this case with an oblique shoreline discretized as a staircase shape, the specular direction, defined from the pattern of wet neighbors, is oscillating between directions 3 and 2, which differ by $30^{\circ}$, which is causing an extra broadening of the reflected spectrum away from the boundary, such as we show at point P3. This clearly shows the limitations of defining the boundary from the land-sea mask only. For a real straight and oblique shoreline, we would expect a specular reflection with a narrow reflected beam between directions 2 and 3 .

[62] Our reflection scheme is thus better suited for irregular coastlines, which are typically the ones where reflection is strongest [O'Reilly et al., 1999]. Simulations are resolutions where the coast is straight should probably used a different parameterization, with higher values of $m$ giving narrower reflected directional distributions.

[63] Acknowledgments. Wave data were provided by the U.S. National Data Buoy Center and the Coastal Data Information Program and quality controlled as part of the Globwave project, funded by ESA and CNES, thanks to the dedication of J.-F. Piolle and M. Accensi. We thank the operators of the Berkeley Digital Seismic Network, for providing excellent broadband seismic data. F.A. is funded by ERC grant 240009 "IOWAGA" with additional support from the U.S. National Ocean Partnership Program under grant N00014-10-1-0383.

\section{References}

Ardhuin, F., and T. H. C. Herbers (2005), Numerical and physical diffusion: Can wave prediction models resolve directional spread?, J. Atmos. Oceanic Technol., 22(7), 886-895.

Ardhuin, F., and R. Magne (2007), Current effects on scattering of surface gravity waves by bottom topography, J. Fluid Mech., 576, 235-264. 
Ardhuin, F., T. H. C. Herbers, P. F. Jessen, and W. C. O’Reilly (2003), Swell transformation across the continental shelf. Part II: Validation of a spectral energy balance equation, J. Phys. Oceanogr., 33, 1940-1953.

Ardhuin, F., T. H. C. Herbers, K. P. Watts, G. P. van Vledder, R. Jensen, and H. Graber (2007), Swell and slanting fetch effects on wind wave growth, J. Phys. Oceanogr., 37(4), 908-931, doi:10.1175/JPO3039.1.

Ardhuin, F., L. Marié, N. Rascle, P. Forget, and A. Roland (2009), Observation and estimation of Lagrangian, Stokes and Eulerian currents induced by wind and waves at the sea surface, J. Phys. Oceanogr., 39(11), 2820-2838.

Ardhuin, F., et al. (2010), Semi-empirical dissipation source functions for wind-wave models: Part I, Definition, calibration and validation, J. Phys. Oceanogr., 40(9), 1917-1941.

Ardhuin, F., E. Stutzmann, M. Schimmel, and A. Mangeney (2011a) Ocean wave sources of seismic noise, J. Geophys. Res., 116, C09004, doi:10.1029/2011JC006952.

Ardhuin, F., J. Hanafin, Y. Quilfen, B. Chapron, P. Queffeulou, M. Obrebski, J. Sienkiewicz, and D. Vandemark (2011b), Calibration of the IOWAGA global wave hindcast (1991-2011) using ECMWF and CFSR winds, paper presented at 12th International Workshop on Wave Hindcasting and Forecasting, Environ. Can., Kohala Coast, Hawaii.

Ardhuin, F., J. Tournadre, P. Queffelou, and F. Girard-Ardhuin (2011c), Observation and parameterization of small icebergs: Drifting breakwaters in the Southern Ocean, Ocean Modell., 39, 405-410, doi:10.1016/ j.ocemod.2011.03.004

Ardhuin, F., A. Balanche, E. Stutzmann, and M. Obrebski (2012), From seismic noise to ocean wave parameters: General methods and validation, J. Geophys. Res., 117, C05002, doi:10.1029/2011JC007449.

Banner, M. L., and I. R. Young (1994), Modeling spectral dissipation in the evolution of wind waves. Part I: Assessment of existing model performance, J. Phys. Oceanogr., 24(7), 1550-1570.

Benoit, M., F. Marcos, and F. Becq (1996), Development of a third generation shallow-water wave model with unstructured spatial meshing, paper presented at 25th International Conference on Coastal Engineering, Am. Soc. of Civ. Eng., Orlando, Fla.

Biesel, F., and N. Ranson (1961), Calculs de diffraction de la houle, paper presented at International Association for Hydro-Environment Engineering and Research Conference, Dubrovnik, Yougoslavia.

Booij, N., R. C. Ris, and L. H. Holthuijsen (1999), A third-generation wave model for coastal regions: 1 . Model description and validation, J. Geophys. Res., 104(C4), 7649-7666.

Bromirski, P. D., R. E. Flick, and N. Graham (1999), Ocean wave height determined from inland seismometer data: Implications for investigating wave climate changes in the NE Pacific, J. Geophys. Res., 104(C9), 20,753-20,766.

Csík, Á., M. Ricchiuto, and H. Deconinck (2002), A conservative formulation of the multidimensional upwind residual distribution schemes for general nonlinear conservation laws, J. Comp. Phys., 172(2), 286-312.

Elgar, S., T. H. C. Herbers, and R. T. Guza (1994), Reflection of ocean surface gravity waves from a natural beach, J. Phys. Oceanogr., 24(7), 1503-1511

Fabrikant, A. L., and M. A. Raevsky (1994), The influence of drift flow turbulence on surface gravity wave propagation, J. Fluid Mech., 262, $141-156$.

Farrell, W. E., and W. Munk (2010), Booms and busts in the deep, J. Phys. Oceanogr., 40(9), 2159-2169.

Guza, R. T., and W. C. O'Reilly (2001), Wave prediction in the Santa Barbara channel, technical report, Pac. Outer Cont. Shelf Reg., Miner. Manage. Serv., U. S. Dep. of the Inter., Washington, D. C.

Hasselmann, K. (1963), A statistical analysis of the generation of microseisms, Rev. Geophys., 1(2), 177-210.

Hasselmann, S., K. Hasselmann, J. Allender, and T. Barnett (1985), Computation and parameterizations of the nonlinear energy transfer in a gravitywave spectrum. Part II: Parameterizations of the nonlinear energy transfer for application in wave models, J. Phys. Oceanogr., 15, 1378-1391.

Herbers, T. H. C., and R. T. Guza (1991), Wind-wave nonlinearity observed at the sea floor. Part I: Forced-wave energy, J. Phys. Oceanogr., 21, $1740-1761$

Herbers, T. H. C., and R. T. Guza (1994), Nonlinear wave interactions and high-frequency seafloor pressure, J. Geophys. Res., 99, 10,035-10,048.

Holthuijsen, L. H., A. Herman, and N. Booij (2003), Phase-decoupled refraction-diffraction for spectral wave models, Coastal Eng., 49, 291-305.

Ilic, S., A. J. van der Westhuysen, J. Roelvink, and A. Chadwick (2007), Multidirectional wave transformation around detached breakwaters, Coastal Eng., 54, 775-789.

Kedar, S., M. Longuet-Higgins, F. W. N. Graham, R. Clayton, and C. Jones (2008), The origin of deep ocean microseisms in the north Atlantic ocean, Proc. R. Soc. London A, 464, 777-793, doi:10.1098/rspa.2007.0277.
Krogstad, H. E., and K. Trulsen (2010), Interpretations and observations of ocean wave spectra, Ocean Dyn., 62, 973-991.

Kuik, A. J., G. P. van Vledder, and L. H. Holthuijsen (1988), A method for the routine analysis of pitch-and-roll buoy wave data, J. Phys. Oceanogr., $18,1020-1034$

Leonard, B. P. (1991), The ULTIMATE conservative difference scheme applied to unsteady one-dimensional advection, Comput. Methods Appl. Mech. Eng., 88, 17-74.

Liau, J.-M., A. Roland, T.-W. Hsu, S.-H. Ou, and Y.-T. Li (2011), Wave refraction-diffraction effect in the wind wave model WWM, Coastal Eng., 58, 429-443.

Longuet-Higgins, M. S. (1950), A theory of the origin of microseisms, Philos. Trans. $R$. Soc. London A, 243, 1-35.

Miche, A. (1951), Le pouvoir réfléchissant des ouvrages maritimes exposés à l'action de la houle, Ann. Ponts Chaussees, 121, 285-319.

National Geophysical Data Center (2011), U.S. Coastal Relief Model, http://www.ngdc.noaa.gov/mgg/coastal/crm.html, Natl. Oceanic and Atmos. Admin., Boulder, Colo.

Nelson, R. C., and J. Gonsalves (1990), A field study of wave reflections from an exposed dissipative beach, Coastal Eng., 14, 457-477.

O'Reilly, W. C., T. H. C. Herbers, R. J. Seymour, and R. T. Guza (1996), A comparison of directional buoy and fixed platform measurements of Pacific swell, J. Atmos. Oceanic Technol., 13, 231-238.

O'Reilly, W. C., R. T. Guza, and R. J. Seymour (1999), Wave prediction in the Santa Barbara channel, final technical report, Pac. Outer Cont. Shelf Reg., Miner. Manage. Serv., U. S. Dep. of the Inter., Washington, D. C. [Available at http://www.coastalresearchcenter.ucsb.edu/cmi/files/2001 055.pdf.]

Rascle, N., F. Ardhuin, P. Queffeulou, and D. Croizé-Fillon (2008), A global wave parameter database for geophysical applications. Part 1 : Wave-current-turbulence interaction parameters for the open ocean based on traditional parameterizations, Ocean Modell., 25, 154-171, doi:10.1016/j.ocemod.2008.07.006

Roland, A. (2008), Development of WWM II: Spectral wave modelling on unstructured meshes, Ph.D. thesis, Inst. of Hydraul. and Water Resour. Eng., Techn. Univer. Darmstadt, Darmstadt, Germany.

Roland, A., A. Cucco, C. Ferrarin, T.-W. Hsu, J.-M. Liau, S.-H. Ou, G. Umgiesser, and U. Zanke (2009), On the development and verification of a 2-D coupled wave-current model on unstructured meshes, J. Mar. Syst., 78, S244-S254.

Schimmel, M., E. Stutzmann, F. Ardhuin, and J. Gallart (2011), Polarized Earth's ambient microseismic noise, Geochem. Geophys. Geosyst., 12 Q07014, doi:10.1029/2011GC003661.

Sportisse, B. (2000), An analysis of operator splitting techniques in the stiff case, J. Comput. Phys., 161(1), 140-168, doi:10.1006/jcph.2000.6495.

Stockdon, H. F., R. A. Holman, P. A. Howd, and A. H. Sallenger Jr. (2006), Empirical parameterization of setup, swash, and runup, Coastal Eng., 53, 573-588

Stopa, J. E., K. F. Cheung, M. A. Garcés, and D. Fee (2010), Source of microbaroms from tropical cyclone waves, Geophys. Res. Lett., 38, L05602, doi:10.1029/2010GL046390.

Sutherland, J., and T. O'Donoghue (1998), Characteristics of wave reflection spectra, J. Waterw. Port Coastal Ocean Eng., 124(6), 303-311.

Szelwis, R. (1982), Modeling of microseismic surface wave source, J. Geophys. Res., 87, 6906-6918.

Taira, K., and Y. Nagata (1968), Experimental study of wave reflection by a sloping beach, J. Oceanogr. Soc. Jpn., 24, 242-252.

Toledo, Y., T.-W. Hsu, and A. Roland (2012), Extended time-dependent mild-slope and wave-action equations for wave-bottom and wave-curren interactions, Proc. R. Soc. London A, 468, 184-205, doi:10.1098/ rspa.2011.037.

Tolman, H. L. (2002), Alleviating the garden sprinkler effect in wind wave models, Ocean Modell., 4, 269-289.

Tolman, H. L., M. L. Banner, and J. M. Kaihatu (2011), The NOPP operational wave improvement project, paper presented at 12th Int. WOrkshop of Wave Hindcasting and Forecasting, Environ. Can., Kohala Coast, Hawaii.

Wessel, P., and W. H. F. Smith (1996), A global self-consistent hierarchical, high-resolution shoreline database, J. Geophys. Res., 101, 8741-8743.

WISE Group (2007), Wave modelling - The state of the art, Prog. Oceanogr. 75, 603-674, doi:10.1016/j.pocean.2007.05.005.

Yanenko, N. N. (1971), The Method of Fractional Steps: The Solution of Problems of Mathematical Physics in Several Variables, Springer, Berlin. Yu, J., and C. C. Mei (2000), Do longshore bars shelter the shore?, J. Fluid Mech., 404, 251-268. 